\title{
OPEN A KLK4 proteinase substrate capture approach to antagonize PAR1
}

\author{
Eitan Rabinovitch ${ }^{1}$, Koishiro Mihara ${ }^{2}$, Amiram Sananes ${ }^{1}$, Marianna Zaretsky ${ }^{3}$, \\ Michael Heyne ${ }^{1,4}$, Julia Shifman ${ }^{4}$, Amir Aharoni ${ }^{3}$, Morley D. Hollenberg ${ }^{2}$ \& Niv Papo ${ }^{1 凶}$
}

Proteinase-activated receptor-1 (PAR1), triggered by thrombin and other serine proteinases such as tissue kallikrein-4 (KLK4), is a key driver of inflammation, tumor invasiveness and tumor metastasis. The PAR1 transmembrane G-protein-coupled receptor therefore represents an attractive target for therapeutic inhibitors. We thus used a computational design to develop a new PAR1 antagonist, namely, a catalytically inactive human KLK4 that acts as a proteinase substrate-capture reagent, preventing receptor cleavage (and hence activation) by binding to and occluding the extracellular R41S42 canonical PAR1 proteolytic activation site. On the basis of in silico site-saturation mutagenesis,

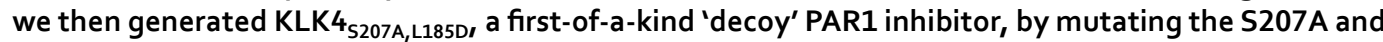
L185D residues in wild-type KLK4, which strongly binds to PAR1. KLK4 \$207A, L185D $_{\text {markedly inhibited }}$ PAR1 cleavage, and PAR1-mediated MAPK/ERK activation as well as the migration and invasiveness of melanoma cells. This 'substrate-capturing' KLK4 variant, engineered to bind to PAR1, illustrates proof of principle for the utility of a KLK4 'proteinase substrate capture' approach to regulate proteinasemediated PAR1 signaling.

Activation of the G-protein-coupled receptor (GPCR) family of proteinase-activated receptors (PARs) by certain extracellular serine proteinases is known to trigger cell signaling. The activation of PARs is initiated by enzymatic cleavage of their extracellular $\mathrm{N}$-terminal sequence to expose a 'tethered ligand' that binds to sites on the extracellular PAR domains to trigger PAR-mediated cell signaling. The first potent activator of PAR1 to be identified and characterized was thrombin, a serine protease that cleaves PAR1 at its 'canonical' extracellular cleavage site between residues R41 and $\mathrm{S} 42^{2}$. It was subsequently found that members of the kallikrein-related peptidase (KLK) family of serine proteinases are also able to cleave/activate PARs ${ }^{3}$. KLK4, KLK5, KLK6 and KLK13 cleave PAR1 at the canonical R41-S42 site, and KLK13 also cleaves PAR1 at position R46-N47 ${ }^{4}$. A variety of other proteinases were found to regulate PAR1 activation by cleaving bonds within the A33 to E57 N-terminal sequence of human PAR1 at distinct sites both upstream and downstream of the 'tethered ligand' sequence ${ }^{5}$. These PAR-regulating proteinases include the matrix metalloproteinases MMP1, MMP2 and MMP13. Of note, the coagulation proteinase, activated protein C (APC), cleaves PAR1 at its R46/N47 site to unmask a tethered ligand sequence, thereby conferring biased signaling that differs from the activation of PAR 1 by thrombin ${ }^{6}$. Thus, the PAR1 N-terminal sequence ${ }^{33}$ ATNATLDPRSFLLRNPNDKYEPFWE ${ }^{57}$ constitutes a common target in the sequence of PAR1 for activation by a variety of proteinases.

Following activation by extracellular proteinases, including members of the KLK family, PAR1 plays significant roles in many normal physiological processes, such as coagulation ${ }^{7}$, inflammation ${ }^{8}$, and vascular homeostasis ${ }^{9}$, but it also contributes to some inflammatory ${ }^{10}$ and cardiovascular pathologies, including atherosclerosis ${ }^{11}$, restenosis ${ }^{12}$, and thrombosis ${ }^{13}$, and to the progression of some cancers by stimulating cell migration and tissue invasion. Indeed, there is a strong correlation between PAR1 expression and the progression of lung ${ }^{14}$, prostate ${ }^{15}$, gastric $^{5}$ and ovarian ${ }^{16}$ cancers and of melanoma ${ }^{17}$. In lung, ovarian and breast cancers and in melanoma, the activation of PAR1 promotes invasiveness and tumorigenicity ${ }^{18-21}$. For example, Boire et al. showed that MMP1 activation of PAR1 promoted invasiveness and tumorigenesis of breast cancer cells in xenograft models ${ }^{19}$; Villares et al. showed that in-vivo treatment of melanoma-bearing mice with PAR1 siRNA inhibited melanoma

\footnotetext{
${ }^{1}$ Avram and Stella Goldstein-Goren Department of Biotechnology Engineering, National Institute of Biotechnology in the Negev, Ben-Gurion University of the Negev, P.O.B. 653, 84105 Beer-Sheva, Israel. ${ }^{2}$ Department of Physiology and Pharmacology, Cumming School of Medicine, University of Calgary, Calgary, Canada. ${ }^{3}$ Department of Life Sciences, National Institute of Biotechnology in the Negev, Ben-Gurion University of the Negev, Beer-Sheva, Israel. "Department of Biological Chemistry, The Hebrew University of Jerusalem, Givat Ram Campus, 91906 Jerusalem, Israel. ${ }^{\circledR}$ email: papo@bgu.ac.il
} 
growth and metastasis 22 ; and Adams et al. showed that PAR1 expressed by tumor stromal cells promoted colon cancer growth in vivo ${ }^{22,23}$.

The KLK family of serine proteinases represents the largest cluster of serine proteinases in the human genome. Expressed in a wide variety of tissues, the kallikrein-related peptidases are implicated in numerous pathophysiologies, ranging from cancers to skin disorders, such as Netherton syndrome ${ }^{24-26}$. Although the KLKs serve as attractive therapeutic targets in the management of certain inflammatory diseases and cancers, the development of selective KLK-targeted enzyme inhibitors represents a challenge ${ }^{27}$, due to the structural similarity, especially at the catalytic site, of KLK family members. In light of the potential role played by KLK4 (having a sequence homology of $31.64 \%$ with thrombin) in prostate cancer via activating either PAR1 or PAR2 ${ }^{28}$, we sought to develop a strategy, alternative to generating a KLK4-specific enzyme inhibitor, to prevent KLK4-stimulated activation of PAR1. We thus aimed to prevent the ability of KLK4 to cleave/activate PAR1 by designing a highaffinity catalytically inactive KLK4 that could act as a 'decoy' substrate-capturing reagent by binding to PAR1 and thereby masking the activation site and blocking PAR1 activation by the proteolytically active wild-type KLK4.

Below we describe our novel approach for selectively blocking PAR1 activation by KLK4 and, by extension, other proteinases like the KLKs that might be present in the microenvironment of tumors ${ }^{29}$ and in inflammatory tissues. Our strategy is derived from the protease 'substrate-capture or trapping' approach, as recently reviewed ${ }^{30}$. This strategy uses catalytically inactive proteinases that bind to, but do not cleave, a substrate. Our approach to inhibitor design comprised engineering an inactive mutant of KLK4 to bind to PAR1 with higher than natural affinity, thus converting it from a PAR1 agonist to a PAR1 antagonist. Since proteases, such as KLK4, are difficult to engineer by applying directed evolution approaches, we utilized a purely computational method for KLK4 engineering before preparing the mutant proteins in the laboratory. Using a computational design, we generated a first-of-a-kind PAR1 inhibitor by mutating the S207A and L185D residues in wild-type KLK4, a natural activator of PAR1 that strongly binds to PAR1. The strong binding of the mutant protein, designated KLK4 $4_{S 207 \mathrm{~A}, \mathrm{~L} 185 \mathrm{D}}$, to the extracellular $\mathrm{N}$-terminal region of PAR1 blocked the canonical cleavage site of PAR1, thereby preventing the activation of PAR1 by KLK4. To demonstrate the potential of our newly designed inhibitor of PAR1-activating proteinases present in the tumor microenvironment, we investigated its ability to inhibit PAR1 activation in PAR1-overexpressing cancer cells, and to block the migration and invasion of human melanoma cells lines that endogenously expresses PAR $1{ }^{17}$, namely, WM3682 and the highly invasive line WM3314. Our results provide an evaluation of the potential of using the proteinase substrate-capture strategy to block the cleavage/activation of a selected proteinase target, namely, PAR1.

\section{Results}

Predicting mutations in KLK4 that increase its affinity for the PAR1 peptide. The in-silico saturation mutagenesis approach previously developed in our group allows us to predict affinity-enhancing mutations in any protein-protein interaction by starting from a high-resolution structure of the protein complex. Since the structure of the KLK4/PAR1 complex as such is not available, we modeled the structure of this complex by using the structure of KLK4 and the structure of thrombin (which is homologous to KLK4) interacting with PAR1 (see Methods). Using this modeled structure of the KLK4/PAR1 complex, we identified the binding interface of KLK4, namely, the 14 positions that interact directly with the PAR1 peptide. At these 14 positions, we introduced all possible mutations, one at a time, and computed the change in free energy of binding due to each mutation (Fig. 1a). This step enabled us to predict a number of affinity-enhancing mutations at several KLK4 positions (Fig. 1a). We then visually inspected each predicted affinity-enhancing mutation in the modeled KLK4/PAR1 structure, since experimentally we could only assay a small number of mutants. Our inspection showed that the most promising mutations were those at positions 89, 204 and, particularly, 98 and 185, for which strongly affinity-increasing mutations were predicted.

Expression, purification and characterization of KLK4 mutants. The KLK4 variants selected for expression and purification all included the mutation S207A (or Ser195 according to chymotrypsin numbering; a member of the catalytic triad, which was previously reported to abolish the catalytic activity of KLK $4^{31}$ ) and an additional mutation at either position E98 or position L185 (which both showed the highest potential for affinity increase by our calculations). The double KLK4 mutants tested were thus those with the S207A mutation in addition to one of the following mutations: E98I, E98Y, E98F, L185S, L185Q, L185N, L185H, L185R, L185K, $\mathrm{L} 185 \mathrm{E}$, or L185D. The active protease, $\mathrm{KLK} 4_{\mathrm{WT}}$, and the inactive low-affinity single mutant, KLK $4_{\mathrm{S} 207 \mathrm{~A}}$, were also purified and used as controls.

To test which of the catalytically inactive KLK4 mutants exhibited increased affinity to the PAR1 peptide, the mutants were expressed and purified as soluble proteins using the Pichia pastoris yeast strain and the pPic9K expression vector, a methodology that allows the purification of the recombinant proteins from the growth medium. All variants were expressed as zymogens (inactive enzyme forms in which a pro-peptide, with the sequence $\mathrm{S}^{27} \mathrm{CSQ}^{30}$, is fused to the N-terminus of the enzyme) tagged with a FLAG tag on the N-terminus and a $6 \times$ His tag on the C-terminus. Activation of the enzyme was achieved with thermolysin by cleavage of the bond between the pro-peptide and peptidase domain. Western blot analysis verified the expression of all KLK4 vari-

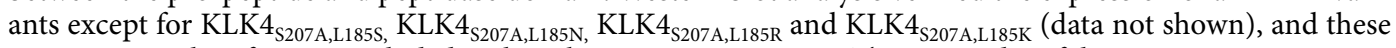
mutants were therefore not included in the subsequent experiments. The remainder of the KLK4 protein variants were purified using Ni-NTA affinity column, analyzed by mass spectrometry (Fig. S1), and activated with thermolysin to remove the N-terminus pro-domain, followed by size-exclusion chromatography (Fig. 1b,c, Fig. S1).

Before proceeding with the subsequent experiments, it was necessary to confirm that the secondary structure of KLK4 had not been altered upon generation of the S207A and L185D point mutations. To this end, we

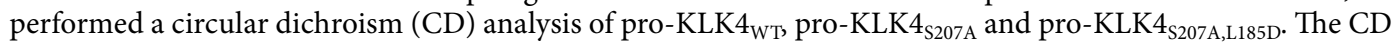


a

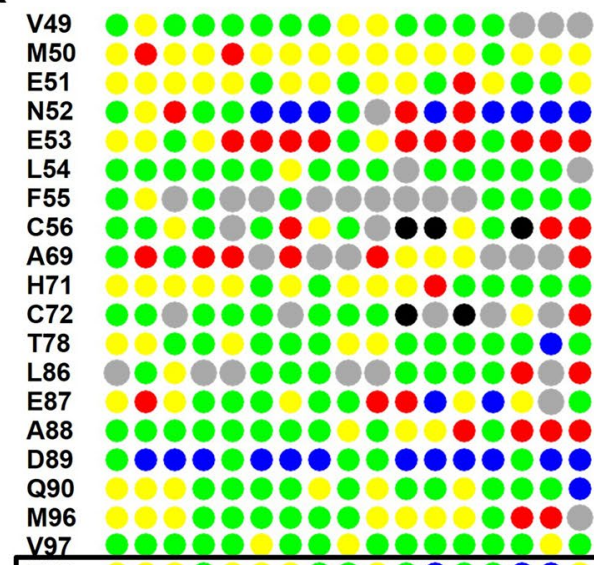

0000 E98

L113 00000000000000

D116 000000000000000

D123 00000000000000000

E124 00000000000000000

壱 L155

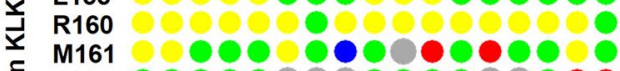

I M161 P162 000000000000000

。 $T 163000000000000000$

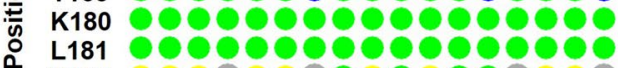

Y182 0000000000000000

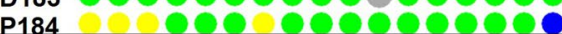

L185 0000000000000000

D201

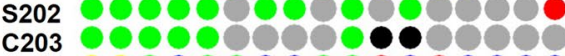

C203

G205 000000000000000

D206 1080080008000898

S207

v221 000000000000000

S222 000000000000000

F223 0000000000000000

G224 00000000000000000

K225

A226 00000000000000000

P227 00000000000000000

C228 0000000000000000

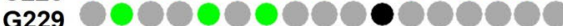

Q230 00000000000000

G235 0000000000000000

V236 00000000000000

A S T Q NHR K E D V L I M Y F W Amino acid mutation Identity b
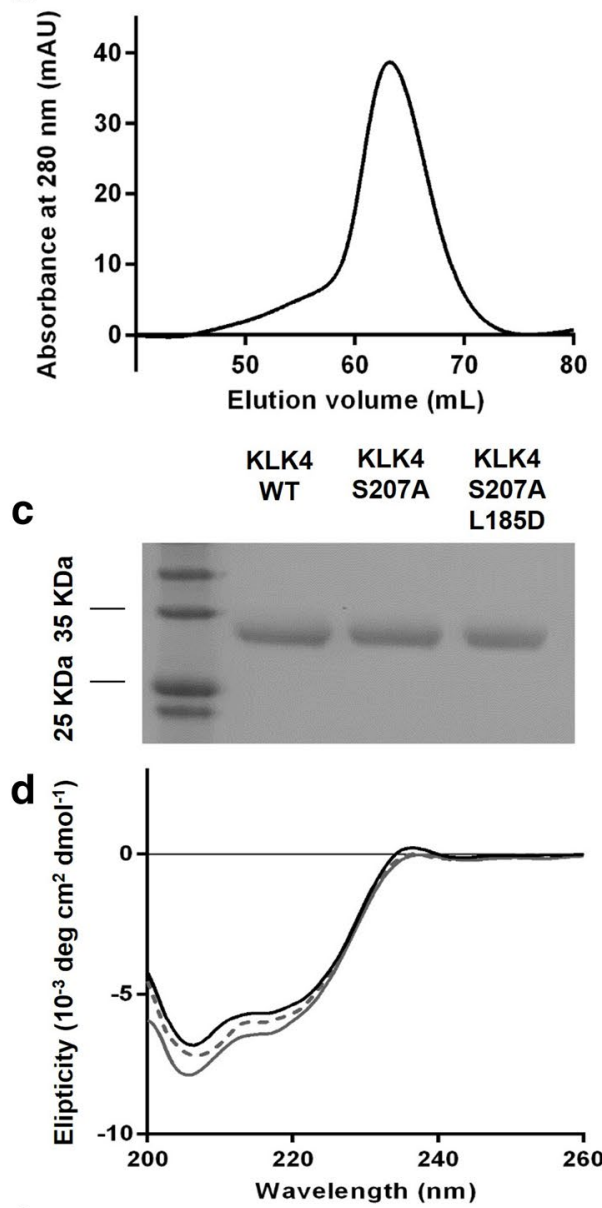

e

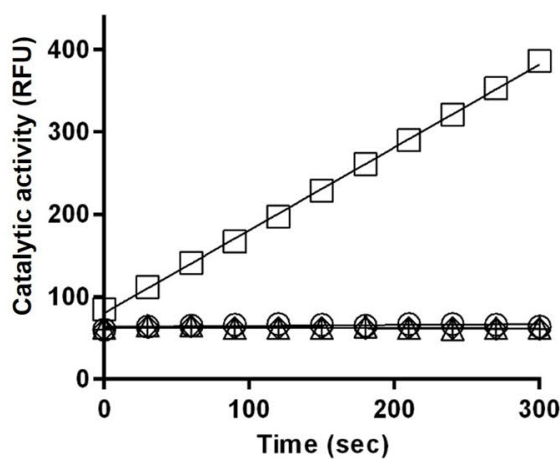

Figure 1. Affinity predictions, purification, and characterization of KLK4 variants. (a) The computational binding landscape of KLK4/PAR1 interactions. KLK4 binding interface residues and their identity in the wildtype sequence are shown on the left, and the amino acids to which they were mutated are shown on the bottom. The change in binding free energies conferred by the mutations are color coded according to the following characteristics: blue-stabilizing, green-neutral, yellow-slightly destabilizing, and red-strongly destabilizing. The gray dots represent mutations that destabilize $\mathrm{KLK} 4_{\mathrm{S} 207 \mathrm{~A}}$. The calculations were performed using the in silico saturation mutagenesis protocol of Sharabi et al. (b) A representative size-exclusion chromatography (SEC) UV absorbance signal of pro-KLK4 proteins (shown here for KLK4 $4_{\mathrm{WT}}$ ) after the Ni-NTA elution purification step. (c) SDS-PAGE of KLK $4_{\mathrm{WT}}$ and of KLK4 $4_{\mathrm{S} 207 \mathrm{~A}}$ and KLK4 $4_{\mathrm{S} 207 \mathrm{~A}, \mathrm{~L} 185 \mathrm{D}}$ as selected purified pro-KLK4 variants. (d) CD spectra of KLK4 $4_{\mathrm{WT}}, \mathrm{KLK} 4_{\mathrm{S} 207 \mathrm{~A}}$ and $\mathrm{KLK} 4_{\mathrm{S} 207 \mathrm{~A}, \mathrm{~L} 185 \mathrm{D}}(10 \mu \mathrm{M})$, as indicated with a solid black line, a dashed line and a solid gray line, respectively. (e) Catalytic activity of KLK4 ${ }_{\mathrm{WT}}$ and the KLK4 variants $\mathrm{KLK} 4_{\mathrm{S} 207 \mathrm{~A}}$ and KLK $4_{\mathrm{S} 207 \mathrm{~A}, \mathrm{~L} 185 \mathrm{D}}$. A BOC-VPR-AMC fluorescent substrate was added to KLK4 $4_{\mathrm{WT}}(\square), \mathrm{KLK} 4_{\mathrm{S} 207 \mathrm{~A}}$ $(\Delta)$, and $\mathrm{KLK} 4_{\mathrm{S} 207 \mathrm{~A}, \mathrm{~L} 185 \mathrm{D}}(\mathrm{O})$, all at final a concentration of $625 \mathrm{nM}$, or to buffer (control, $\diamond$ ), and the fluorescent signal upon substrate cleavage was measured. 


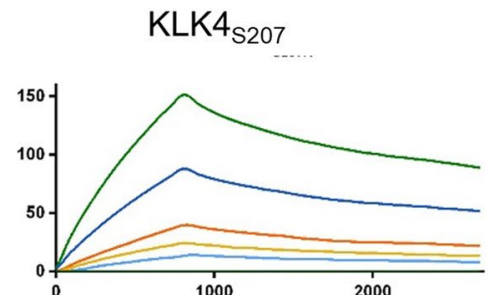

$\mathrm{KLK}_{\text {S207,E981 }}$
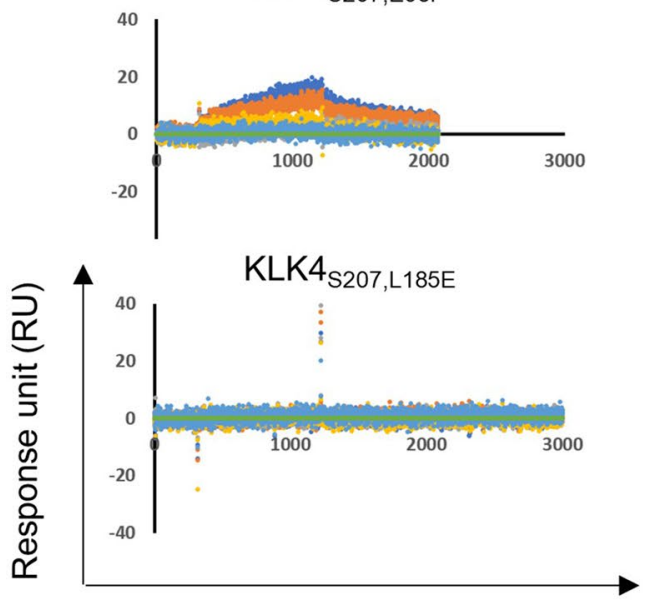

Time (s)
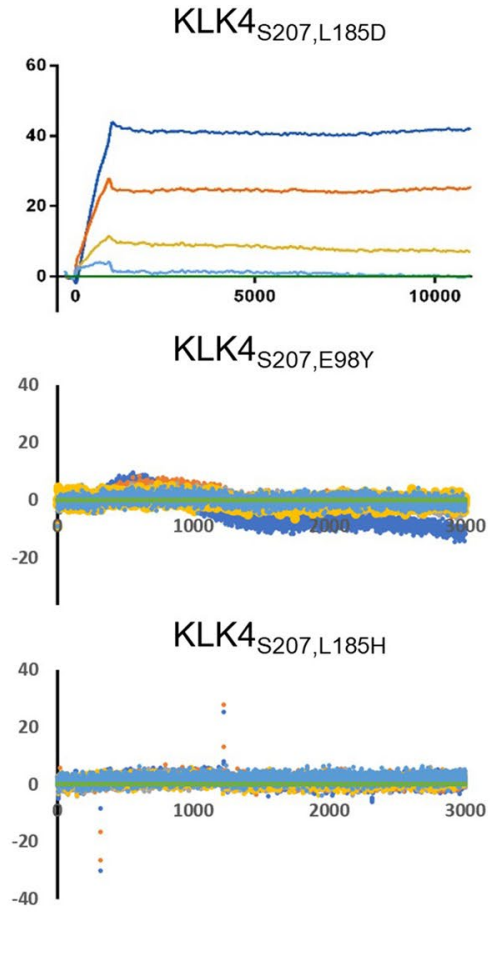

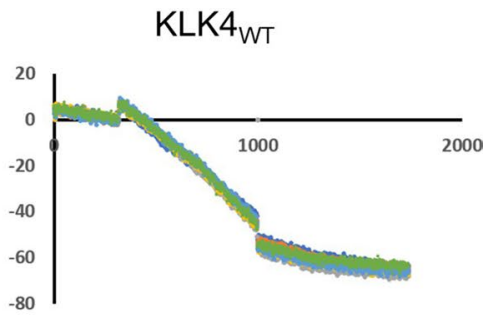

$\mathrm{KLK}_{\text {S207,E98F }}$
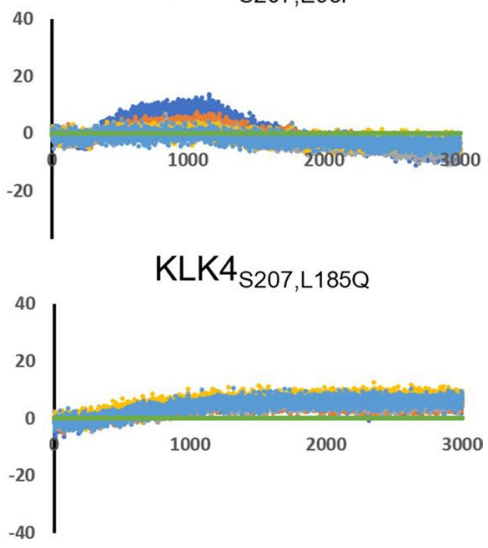

Figure 2. SPR sensorgrams of the binding interactions between a biotinylated PAR1 peptide, immobilized on a ProteOn NLC chip, and soluble KLK4 $4_{S 207 \mathrm{~A}}(0.125-2 \mu \mathrm{M}), \mathrm{KLK}_{\mathrm{S} 207 \mathrm{~A}, \mathrm{~L} 185 \mathrm{D}}(0.5-8 \mu \mathrm{M})$, KLK $4_{\mathrm{WT}}(6.25-100 \mathrm{nM})$, $\mathrm{KLK}_{\mathrm{S} 207 \mathrm{~A}, \mathrm{E} 98 \mathrm{I} / \mathrm{Y} / \mathrm{F}}(0.125-2 \mu \mathrm{M})$ and $\mathrm{KLK}_{\mathrm{S} 207 \mathrm{~A}, \mathrm{~L} 185 \mathrm{E} / \mathrm{H} / \mathrm{Q}}(0.125-2 \mu \mathrm{M})$. The analyses of the association and dissociation of KLK4 variants upon addition to the chip-immobilized PAR1 were carried out for $818 \mathrm{~s}$ and for $30 \mathrm{~min}$, respectively, except for KLK4 $4_{\text {S207AL185D }}$, for which the dissociation step was extended to $166 \mathrm{~min}$.

spectra of the two mutants were very similar to the spectrum of pro-KLK4 $4_{\mathrm{WT}}$ (Fig. 1d), indicating that the secondary structure had remained intact.

The L185D mutation increases the affinity of $K L K 4_{S 207 A}$ to the PAR1 peptide in vitro. To test whether the S207A mutation did indeed abolish the catalytic activity of all the KLK4 mutants tested, the catalytic activity of each mutant (vs. that of $\mathrm{KLK}_{\mathrm{WT}}$ ) was determined by measuring the fluorescent signal generated when reacting it with the Boc-VPR-AMC fluorescent substrate (Fig. 1e). In addition, binding of these proteins to an immobilized PAR1 peptide was determined by SPR (Fig. 2). As expected, only KLK4 $4_{\mathrm{WT}}$ was able to cleave Boc-VPR-AMC, while the S207A mutation abolished the catalytic activity of all the other KLK4 variants. In addition, the SPR results showed that $\mathrm{KLK}_{\mathrm{WT}}$ did not bind to the PAR1 peptide, but instead cleaved it rapidly. $\mathrm{KLK} 4_{\mathrm{S} 207 \mathrm{~A}}$, the catalytically inactive low-affinity mutant, having a single residue mutated in its catalytic pocket, showed no catalytic activity and bound the PAR1 peptide with a $\mathrm{K}_{\mathrm{D}}$ of $1.12 \times 10^{-6} \mathrm{M}$, which was calculated from the affinity rate constants $\mathrm{K}_{\text {on }}\left(3.49 \times 10^{2} \mathrm{M}^{-1} \mathrm{~s}^{-1}\right)$ and $\mathrm{K}_{\text {off }}\left(3.91 \times 10^{-4} \mathrm{~s}^{-1}\right)$. The addition of an affinity-enhancing mutation, such as L185D (giving the KLK $4_{S 207 \mathrm{~A}, \mathrm{L185D}}$ double mutant), increased the affinity of the soluble protein to the PAR1 peptide by 20 -fold $\left(K_{D}=5.55 \times 10^{-8} \mathrm{M}\right)$. The affinity enhancement resulted from an improvement in the dissociation rate $\left(\mathrm{K}_{\mathrm{off}}=3.17 \times 10^{-6} \mathrm{~s}^{-1}\right.$, which was 123 -fold slower than that for the parental KLK4 $\left.4_{\mathrm{S} 207 \mathrm{~A}}\right)$, despite the slower association rate $\left(\mathrm{K}_{\mathrm{on}}=5.7 \times 10 \mathrm{M}^{-1} \mathrm{~s}^{-1}\right)$ (Fig. 2). Thus, the incorporation of the L185D mutation induced stronger and tighter binding to the PAR1 peptide. All the other purified KLK4 double mutants showed no improvement in affinity toward the PAR1 peptide in comparison with KLK4 $4_{\text {S207A }}$ (Fig. 2).

In summary, mutation S207A abolished the catalytic activity of KLK4, and engineering of the mutation L185D into the inactive KLK4 $4_{\text {S207A }}$ variant increased its affinity to the PAR1 peptide by 20 -fold. Therefore, in all subsequent experiments, it was the KLK $4_{\mathrm{S} 207 \mathrm{~A}, \mathrm{~L} 185 \mathrm{D}}$ double mutant that was investigated as a functional antagonist of the PAR1 peptide.

KLK4 $_{\text {S207A, } 185 D}$ inhibits cell-expressed PAR1 cleavage. To test whether KLK4 $4_{\mathrm{S} 207 \mathrm{~A}, \mathrm{~L} 185 \mathrm{D}}$ inhibits cleavage of the full-length wild-type PAR1 transmembrane receptor by KLK4 $4_{\mathrm{WT}}$ (i.e., whether KLK4 $4_{\mathrm{S} 207 \mathrm{~A}, \mathrm{~L} 185 \mathrm{D}}$ serves as a potential PAR1 antagonist) in an in-vitro cellular system, we used the breast cancer MCF7 and melanoma WM3682 cell lines as model systems. The full-length PAR1 protein, fused to an mCherry fluorescent protein at the N-terminus and an eYFP fluorescent protein at the C-terminus, was overexpressed in these cells. As in the wild-type PAR1 protein, the N-terminus (which houses the cleavage site for the KLK4 $4_{\mathrm{WT}}$ peptidase) of the fluorescent fusion PAR1 protein is localized in the extracellular region, and the C-terminus is located in the 
Merge
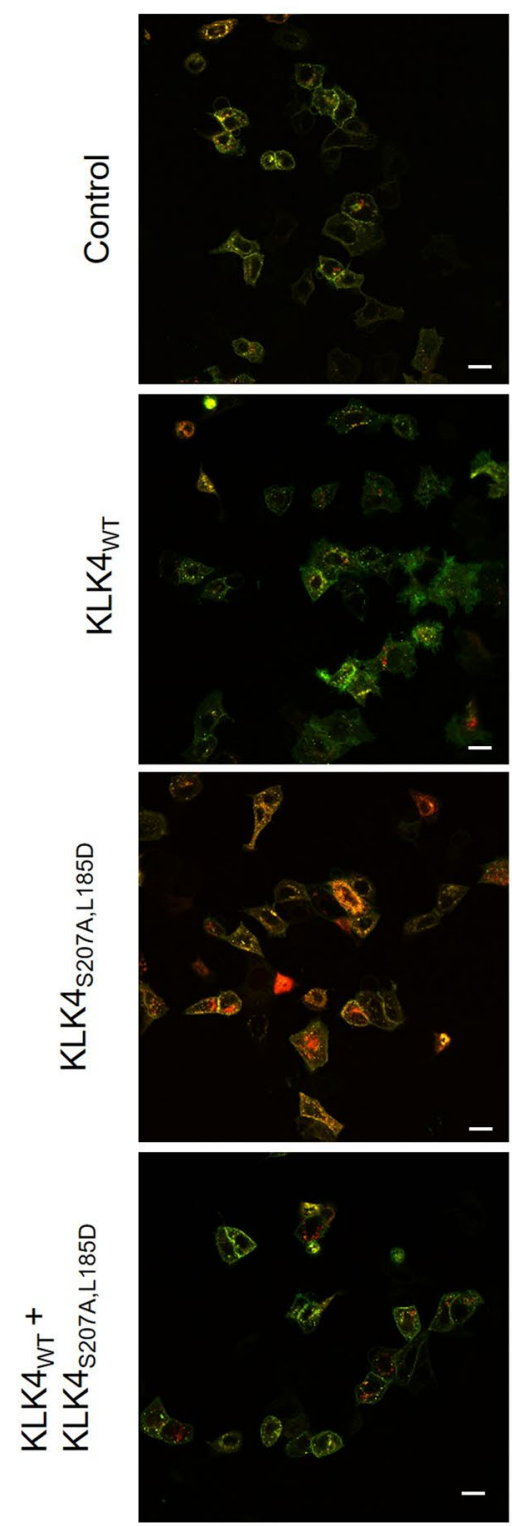

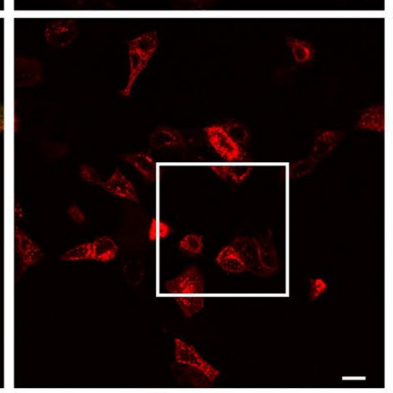

mCherry
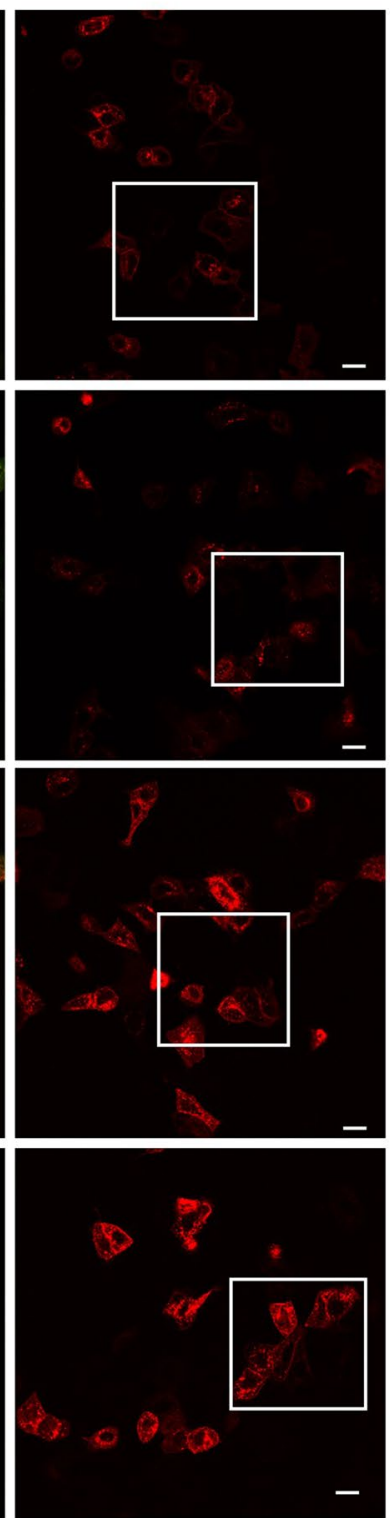

eYFP
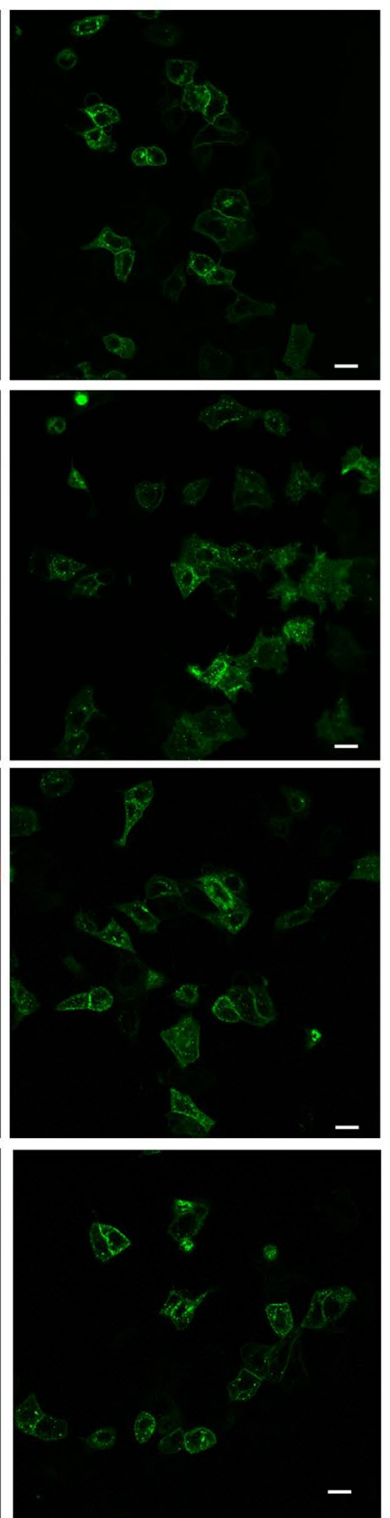

Zoom in
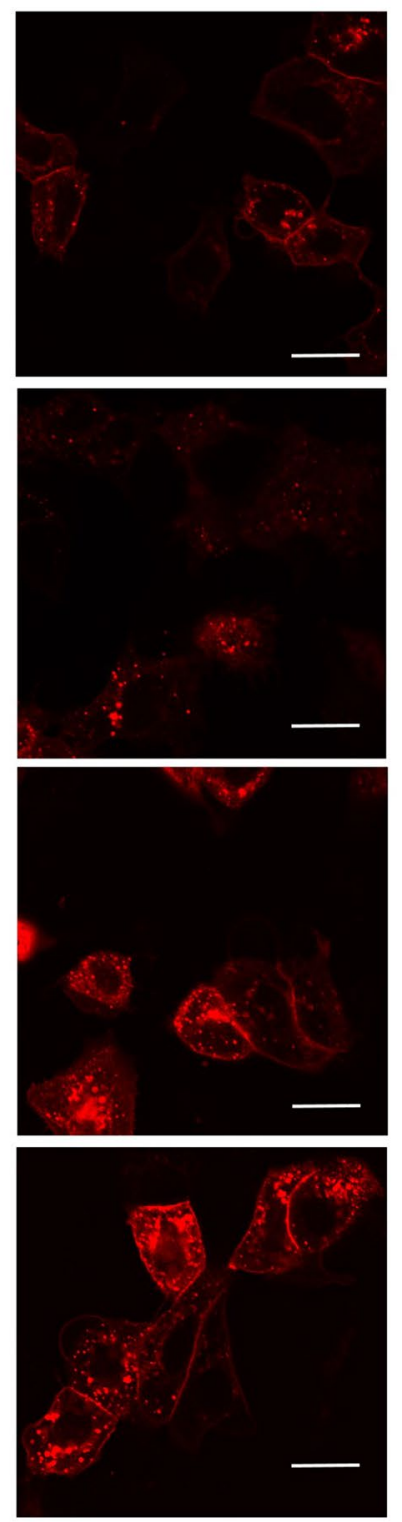

Figure 3. Confocal microscope images of MCF7 breast cancer cells, expressing the mCherry-PAR1-eYFP construct in the presence or absence of $\mathrm{KLK}_{\mathrm{WT}}$ and $\mathrm{KLK} 4_{\mathrm{L} 185 \mathrm{D}, 5207 \mathrm{~A}}$. The right-most column represents a zoom-in view of the white box for each row in the mCherry column and arrows point to a visible membrane mCherry (extracellular PAR1 domain) signal. The red and green channels were used to measure mCherry (extracellular PAR1 domain) and eYFP (intracellular PAR1 domain), respectively. A 20- $\mu \mathrm{m}$ scale bar is indicated as a white bar on the lower right corner of each image.

intracellular region. In both the MCF7 and WM3682 cell lines, cleavage (activation) of PAR1 upon treatment with $100 \mathrm{nM} \mathrm{KLK} 4_{\mathrm{WT}}$ removed the extracellular mCherry, leaving the intracellular eYFP intact (Fig. 3 and Supplementary Fig. S2). As may be seen in the confocal microscopy experiments described here and as was also found in previous studies (e.g. ${ }^{32}$ ), the released mCherry tag appeared to be internalized into the cells. This finding stands in contrast to that for the untreated cells, for which the extracellular domain (mCherry) underwent only a minor cleavage, probably caused by endogenously released extracellular proteases. Notably, addition of $200 \mathrm{nM} \mathrm{KLK} 4_{S 207 \mathrm{~A}, \mathrm{~L} 185 \mathrm{D}}$ together with $100 \mathrm{nM}$ of the catalytically active KLK $4_{\mathrm{WT}}$ inhibited the cleavage of membrane PAR1.

In a complementary, more quantitative, experiment using fluorescence spectroscopy, we showed that treatment of WM3682 cells overexpressing fluorescently labeled PAR1 with a mixture of KLK4 $4_{\mathrm{WT}}$ and KLK4 $4_{\mathrm{S} 207 \mathrm{~A}, \mathrm{~L} 185 \mathrm{D}}$ resulted in a significant, dose-dependent inhibition of PAR1 cleavage in comparison with treatment with KLK $4_{\text {WT }}$

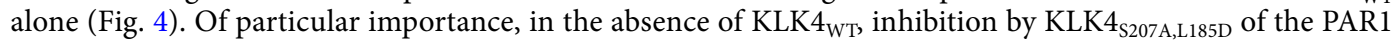
cleavage, presumably mediated by endogenously produced microenvironment proteinases, was also observed. 


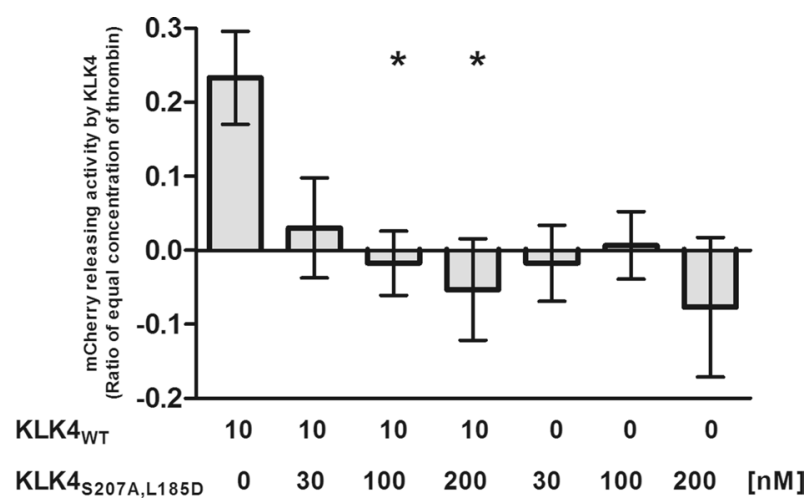

Figure 4. Inhibition by KLK4 $4_{\mathrm{S} 207 \mathrm{~A}, \mathrm{~L} 185 \mathrm{D}}$ of the ability of $\mathrm{KLK} 4_{\mathrm{WT}}$ to cleave the N-terminus of PAR1. Fluorescence of mCherry released from the PAR1 N-terminus by KLK $4_{\mathrm{WT}}$ in the absence or presence of increasing concentrations of the substrate-capture KLK4 $4_{\text {S207A,L185D }}$ mutant of KLK4 was detected in supernatant of mCherry-PAR1-YFP transfected WM3682 indicator cells, as outlined in Methods. The release of the N-terminal mCherry tag of PAR1 by wild-type KLK4 $(1 \mathrm{U} / \mathrm{mL})$ was expressed as a ratio of the release caused by $1 \mathrm{U} / \mathrm{mL} / 10 \mathrm{nM}$ thrombin in the same experiment. The KLK4-mediated cleavage-release of the PAR1 N-terminus was blocked by KLK4 $4_{S 207 \mathrm{~A}, \mathrm{~L} 185 \mathrm{D}}$, which alone did not release the N-terminus (right-hand histograms). Data showing the mCherry release caused by KLK4 relative to that caused by $1 \mathrm{U} / \mathrm{mL}$ thrombin represent the average fluorescence release \pm SEM for 4 replicate monolayer samples. ${ }^{\star}, P<0.05$ by one-way ANOVA for the release in the presence, vs the absence, of KLK4 $4_{S 207 A, L 185 \mathrm{D}}$.

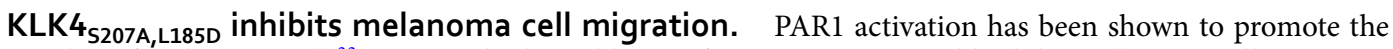
motility of melanoma cells ${ }^{33}$. To test whether addition of KLK4 $4_{\mathrm{S} 207 \mathrm{~A}, \mathrm{~L} 185 \mathrm{D}}$ could inhibit melanoma cell migration via inhibition of PAR1 activation, we performed a scratch-induced migration assay of melanoma WM3682 cells supplemented with different concentrations of KLK4 $4_{\mathrm{S} 207 \mathrm{~A}, \mathrm{~L} 185 \mathrm{D}}($ Fig. 5a and b). Prior to performing this assay, we confirmed that WM3682 cells do indeed express high levels of endogenous PAR1 (by using flow-cytometry; Supplementary Fig. S3a) and that KLK4 $4_{\mathrm{S} 207 \mathrm{~A}, \mathrm{~L} 185 \mathrm{D}}$ does not alter cell proliferation in any way that could result in misinterpretation of the scratch assay results. For the latter purpose, we compared the proliferation after $24 \mathrm{~h}$ of incubation of WM3682 cells treated with $1 \mu \mathrm{M} \mathrm{KLK} 4_{\mathrm{S} 207 \mathrm{~A}, \mathrm{~L} 185 \mathrm{D}}$ with that for untreated cells; the results showed no difference in cell proliferation (Supplementary Fig. S4a). In the scratch assay, addition of $12.5 \mathrm{nM}$ KLK4 $4_{S 207 A, L 185 D}$ to WM3682 cells, immediately after the cell scratch was generated, reduced the spontaneous migration of the cells by $11 \%$ after $24 \mathrm{~h}$ vs. the scratch area covered with untreated control cells. When the concentration of KLK $4_{S 207 \mathrm{~A}, \mathrm{~L} 185 \mathrm{D}}$ was doubled to $25 \mathrm{nM}$, WM3682 cell migration was reduced by $34 \%$, namely,

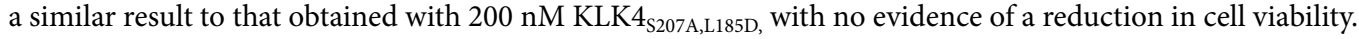

WM3314 melanoma cell invasion is inhibited by KLK4 ${ }_{S 207 A, L 185 D}$. In addition to its contribution to cell motility, PAR1 activation has also been shown to promote metastasis of melanoma cells ${ }^{21}$. To test the ability of KLK4 $4_{\text {S207A,L185D }}$ to inhibit WM3314 melanoma cell invasion, we used a Boyden chamber Matrigel invasion assay. Prior to performing this assay, we confirmed that WM3314 cells express high levels of endogenous PAR1 by using flow-cytometry (Supplementary Fig. S3b). Addition of $10 \%$ fetal bovine serum (FBS) to the medium in the lower compartment of the Boyden set-up resulted in cell invasion from the upper chamber through the Matrigel to the lower compartment. Treatment of the cells in the upper chamber with increasing concentrations of KLK4 $4_{S 207 \mathrm{~A}, \mathrm{L185D}}$ resulted in a dose-dependent inhibition of cell invasiveness (Fig. 5c). When comparing the number of invasive cells upon treatment with $200 \mathrm{nM} \mathrm{KLK} 4_{\mathrm{S} 207 \mathrm{~A}, \mathrm{~L} 185 \mathrm{D}}$ with the number of untreated cells, we found that $33.5 \%$ fewer cells had become invasive upon treatment with KLK $4_{\mathrm{S} 207 \mathrm{~A}, \mathrm{~L} 185 \mathrm{D}}$.

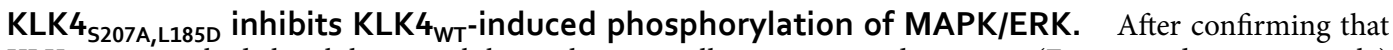
KLK4 $4_{S 207 A, L 185 \mathrm{D}}$ had the ability to inhibit melanoma cell migration and invasion (Fig. 5a and c, respectively) by inhibiting PAR1 cleavage by $\mathrm{KLK}_{\mathrm{WT}}$ or other endogenous proteases (as shown by the confocal microscopy results in Fig. 3 and Supplementary Fig. S2), we examined the ability of KLK4 $4_{\text {S207A,L185D }}$ to inhibit the activation of MAPK/ERK, which is a major downstream signal produced by PAR1 activation through the $\mathrm{KLK} 4_{\mathrm{WT}}$-induced cleavage of PAR1's extracellular region ${ }^{17}$ and an important downstream signaling effector involved in cell motility ${ }^{34,35}$. To this end, WM3682 melanoma cells were treated either with KLK4 ${ }_{\mathrm{WT}}$ alone to activate MAPK/ERK, or with a combination of KLK $4_{\mathrm{WT}}$ and increasing concentrations of KLK $4_{\mathrm{S} 207 \mathrm{~A}, \mathrm{~L} 185 \mathrm{D}}$, or left untreated (Fig. 5d). The results showed that $10 \mathrm{nM}$ KLK4 induced 61\% enhancement in activation of MAPK/ ERK in comparison with the untreated sample. Addition of $1 \mu \mathrm{M} \mathrm{KLK} 4_{\mathrm{S} 207 \mathrm{~A}, \mathrm{~L} 185 \mathrm{D}}$ completely inhibited the phosphorylation of MAPK/ERK that had been induced by $10 \mathrm{nM} \mathrm{KLK} 4_{\mathrm{WT}}$, producing a signal that was equal to that of the untreated control cells (Fig. 5d and Supplementary Fig. S6). 
a

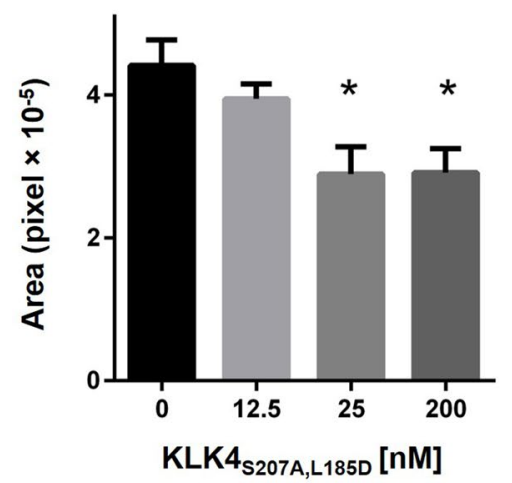

C

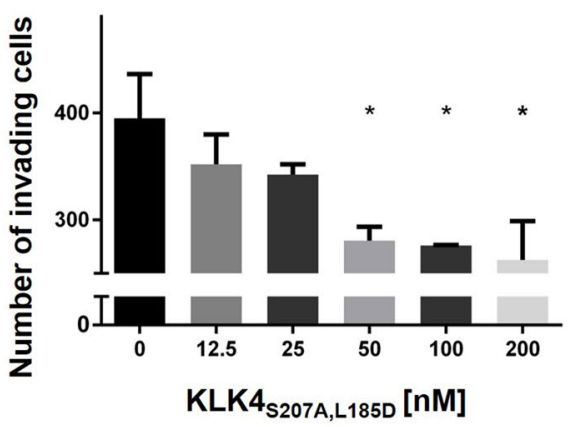

b

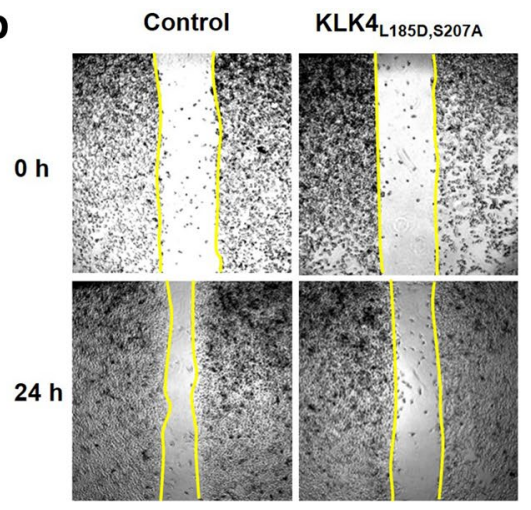

d

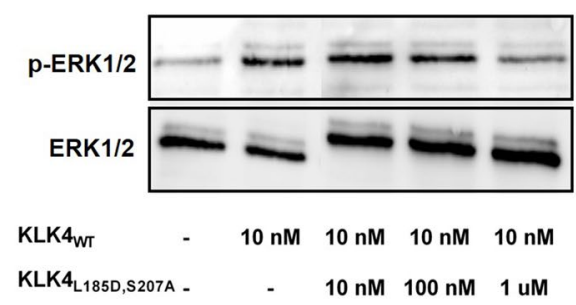

Figure 5. Inhibition of cell invasion, migration and downstream signaling of melanoma cells by KLK $4_{S 207 \mathrm{~A}, \mathrm{~L} 185 \mathrm{D}}$. (a) Inhibition of WM3682 melanoma cell migration as determined by a scratch assay. A monolayer of WM3682 cells was scratched linearly. After the scratch had been generated, the cell culture was supplemented with 0 , $12.5,25$ and $200 \mathrm{nM} \mathrm{KLK} 4_{\mathrm{L} 185 \mathrm{D}, \mathrm{S} 207 \mathrm{~A},}$, and the cells were then imaged by a phase-contrast microscopy, at 0 and $24 \mathrm{~h}$ after the scratch had been made. The relative area covered by cells for each treatment was calculated as the ratio of the scratch gap at $24 \mathrm{~h}$ and the original gap at $0 \mathrm{~h}$. The results are presented as means $\pm \mathrm{SE}(\mathrm{n}=3)$. ${ }^{*} p<0.05$ compared with the untreated control by ANOVA. (b) Representative images of cells that had migrated (from panel a). (c) Inhibition of invasion of WM3314 melanoma cells by KLK4 $4_{\mathrm{L} 185 \mathrm{D} \text {, S207A }}$ was determined in a Boyden chamber invasion assay. The numbers of cells that migrated through the membrane were counted at $18 \mathrm{~h}$ post treatment with $0,12.5,25,50,100$ and $200 \mathrm{nM} \mathrm{KLK} 4_{\mathrm{L} 185 \mathrm{D}, S 207 \mathrm{~A}}$. The results are presented as means $\pm \mathrm{SE}$ $(\mathrm{n}=3) .{ }^{*} p<0.05$ compared with the untreated control by ANOVA. (d) Inhibition of ERK1/2 activation by $\mathrm{KLK}_{\mathrm{L} 185 \mathrm{D}, \mathrm{S} 207 \mathrm{~A}}$. WM3682 cells were treated for $15 \mathrm{~min}$ with PBS, $10 \mathrm{nM} \mathrm{KLK} 4_{\mathrm{WT}}$, or with a mixture of $10 \mathrm{nM}$ $\mathrm{KLK}_{\mathrm{WT}}$ and $10 \mathrm{nM}, 100 \mathrm{nM}$ or $1 \mu \mathrm{M} \mathrm{KLK} 4_{\mathrm{L} 185 \mathrm{D}, \mathrm{S} 207 \mathrm{~A}}$, and analyzed by western blotting for ERK and p-ERK levels.

\section{Discussion}

Our findings establish proof of principle for the utility of the proteinase-capture approach to block the cleavage/ activation of PAR1, a biologically important KLK4 targeted substrate. Although the proteinase-capture approach has previously been used to identify potential substrates by a 'pulldown-proteomic' approach, we believe our work is the first to demonstrate proof of principle for blocking the cleavage/activation of a proteinase substrate, such as PAR1. Using in-silico predictions for affinity-enhancing mutations and experimentally testing several selected double mutants that were based on the catalytically inactive $\mathrm{KLK} 4_{S 207 \mathrm{~A}}$ mutant, we identified a high-

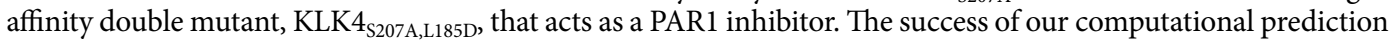
is noteworthy, since no high-resolution structure of the KLK4/PAR1 protein complex was available and modeling such structures tends to reduce the accuracy of predictions. Both catalytic inactivation and affinity enhancement of the $\mathrm{KLK}_{\mathrm{S} 207, \mathrm{~L} 185 \mathrm{D}}$ mutant (expressed and purified in a soluble form), relative to KLK4 ${ }_{\mathrm{WT}}$, were validated using SPR measurements of this mutant in complex with the PAR1 peptide. We thus showed that while a $\sim$ sixfold reduced $k_{\text {on }}$ affinity rate constant was observed for the $\mathrm{KLK}_{\mathrm{S} 207, \mathrm{~L} 185 \mathrm{D}}$ /PAR1 peptide complex compared with that of the $\mathrm{KLK}_{\mathrm{S} 207} / \mathrm{PAR} 1$ peptide complex, the $k_{\text {off }}$ affinity rate was 123 -fold slower for the former, resulting in an 20 -fold overall affinity enhancement for the $\mathrm{KLK}_{\mathrm{S} 207, \mathrm{~L} 185 \mathrm{D}} / \mathrm{PAR} 1$ peptide complex.

The KLK4 $4_{\text {S207A,L185D }}$ 'decoy' substrate-capture enzyme was able to block KLK4- mediated cleavage of PAR1 expressed in MCF7 and WM3682 cell lines (visualized by confocal microscopy and fluorescence spectroscopy). Further, treatment of the MCF7 and WM3682 cells overexpressing fluorescently labeled PAR1 with a mixture of $\mathrm{KLK} 4_{\mathrm{WT}}$ and $\mathrm{KLK} 4_{\mathrm{S} 207 \mathrm{~A}, \mathrm{~L} 185 \mathrm{D}}$ resulted in a significant inhibition of PAR1 cleavage in comparison with treatment with $\mathrm{KLK} 4_{\mathrm{WT}}$ alone. Of added importance, inhibition of PAR1 cleavage, presumably caused by endogenously 
produced microenvironment proteinases, was also observed in the absence of added KLK $4_{\mathrm{WT}}$. This inhibitory effect resulted in reduction in migration induced by unknown PAR1-activating proteinases in the tumor cell microenvironment.

Several cell-secreted proteinases have been suggested as enzymes that can cleave/activate PAR1 in MCF7 cells and may thus serve as agonists of PAR1. MMP1, for example, which cleaves PAR1 at a non-canonical site, between residues D39-P40 24 , was found to be endogenously overexpressed in the MCF7 cell line ${ }^{36}$. Another member of the MMP family, namely, MMP-13, which activates PAR1 at a different non-canonical cleavage site, between residues S42-F43, was also shown to be expressed in MCF7 cells ${ }^{37}$. In addition, other members of the KLK family are known to be expressed in MCF7 breast cancer cells ${ }^{38}$, including: KLK5, which cleaves PAR1 at positions R41-S42 and F43-L44; KLK6, which cleaves PAR1 at positions R41-S42, S42-F43, F43-L44, L45-R46 and R46-N47; and KLK13, which cleaves PAR1 at positions R41-S42, F43-L44, and R46-N47 ${ }^{3}$. It is now known that proteinases, such as MMP1, APC, and neutrophil elastase, can cleave PAR1 at 'non-canonical' sites to stimulate 'biased signaling ${ }^{39}$. To the best of our knowledge, no previous work has been performed to evaluate protease expression in WM3682 cells, but a screen of the Broad Institute Cancer Cell Line Encyclopedia (CCLE) mRNA expression database revealed that $M M P 1$ is highly expressed in most melanoma cell lines, suggesting that it could also be expressed in the WM3682 cell line and could therefore be involved in the cleavage process of PAR1 at a non-canonical cleavage site, between residues D39 and P40 ${ }^{26}$. The KLK4 $4_{\mathrm{S} 207 \mathrm{~A}, \mathrm{~L} 185 \mathrm{D}}$ 'decoy' could, in principle, block PAR1 activation at this site as well as at the 'canonical' activation site.

To investigate how KLK $4_{\text {S207A,L185D }}$ interacts with the PAR1 extracellular region at the molecular level to block activation at both canonical and non-canonical cleavage sites, we examined the interaction of KLK $4_{\text {S207A,L185D }}$ with the PAR1 extracellular region. Structural analysis of the modeled KLK4/PAR1 complex structure showed that the affinity enhancement in the $\mathrm{KLK}_{\mathrm{S} 207 \mathrm{~A}, \mathrm{~L} 185 \mathrm{D}} / \mathrm{PAR} 1$ complex (Supplementary Fig. S5a) is probably due the formation of a new hydrogen bond between the mutated L185D residue in KLK4 and residue N35 (a residue excluded from the canonical cleavage site) in the PAR1 peptide (Supplementary Fig. S5b). Moreover, as previously described, a negatively charged surface patch on KLK4 (between loop M50-E53 and loop D89-Q95) could serve as a recognition site for binding with the hirudin-like domain on PAR1 (residues 51-55, KYEPF) (Supplementary Fig. S5a), similar to the interaction of PAR1 with the anion-binding exosite of thrombin (exosite 1) ${ }^{4,33,40,41}$. In addition, we predicted that additional hydrogen bonds could be formed between residues F55, G215, S222 and G224 of the mutated catalytic pocket in KLK $4_{\text {S207A,L185D }}$ and residues D39, R41 and S42 in PAR1 (Supplementary Fig. S5c). These hydrogen bonds could be formed in addition to the electrostatic interactions predicted between the positively charged R41 in PAR1 that becomes buried within the negatively charged surface cavity of KLK4 in the PAR1/KLK $\mathrm{S}_{\mathrm{S} 207 \mathrm{~A}, \mathrm{L185D}}$ complex (Supplementary Fig. S5d); these hydrogen bonds might, in fact, be the same interactions that mediate the cleavage of PAR1 by KLK4 $4_{\mathrm{WT}}$. All the above-predicted interactions between KLK4 $4_{\text {S207A,L185D }}$ and PAR1 would probably 'hold' PAR1 residues $35-55$ in close proximity to KLK $4_{\text {S207A,L185D, }}$, thereby blocking the access of other proteases and preventing them from cleaving PAR1 anywhere between residues $35-55$.

In summary, we have established proof of principle for converting a PAR1-activating proteinase into a highaffinity substrate-capture antagonist, using KLK4 as a prototype enzyme present in the microenvironment of many tumors. The use of our substrate capture approach has also expanded the understanding of the activation of PAR1 and its potential contribution to melanoma invasion. As an antagonist strategy, our approach could be used not only to target PAR1 activation in selected settings, but also to block the proteinase-mediated generation of active polypeptides from their precursors in the tumor microenvironment.

\section{Materials and methods}

Modeling the KLK4/PAR1 complex structure. The structure of the PAR1 extracellular peptide $\left({ }^{33}\right.$ ATNATLDPRSFLLRNPNDKYEPFWE $\left.{ }^{57}\right)$ in complex with KLK4 was modeled on the basis of the available crystal structures of a thrombin/PAR1 complex (PDB-ID 3LU9) ${ }^{42}$ and the structure of the wild-type KLK4 $(\mathrm{PDB}-\mathrm{ID} 4 \mathrm{~K} 8 \mathrm{Y})^{43}$. Missing residues were added using the Modeller suit ${ }^{44}$. All water molecules and ions were removed. The crystal structure of KLK4 was aligned with that of thrombin (which is homologous to KLK4) in 3LU9, and the modeled PAR1 peptide was aligned with PAR1 of the same crystal structure. The resulting KLK4/ PAR1 complex structure was optimized using FlexPepDock ${ }^{45,46}$, and the best ranked model according to the Rosetta generic full-atom energy score was used as the input to the in-silico saturation mutagenesis protocol.

In-silico saturation mutagenesis of selected positions in the KLK4/PAR1 interface. The modeled structure of the KLK4/PAR1 complex was used as the input for all calculations, and hydrogen atoms were added to the structure by MolProbity ${ }^{47}$. The KLK4 residues within $4 \AA$ of the PAR1 peptide in the modeled KLK4/PAR1 complex structure were identified as the binding interface positions (KLK4 positions 49-56, 69, $71-72,78,86-90,96-98,108,113,116,123-124,155,160-163,180-185,201-207,221-230$, 235-236). For each of the above positions, we defined a set of shell positions that included the residues on KLK4 that are within $3 \AA$ of the KLK4 position to be mutated and the residues on PAR1 that are within $5 \AA$ of the KLK4 position. For each binding interface position, we then performed 17 calculations, in which the considered position on KLK4 was either kept as wild type or was replaced with any other amino acid, except proline, cysteine, or glycine. During the calculation, the shell and the interface residues were repacked, and the energies of the KLK4/PAR1 complexes were calculated for the wild-type and mutated complexes. The two proteins in each complex were then separated to enable calculation of the energy of each unbound chain separately without further repacking of the side chains. The intermolecular energy was calculated by subtracting the energies of the single chains from the total energy of the complex. $\Delta \Delta G_{\text {bind }}$ was calculated as the intermolecular energy of the mutated complex minus the intermolecular energy of the wild-type complex. The obtained $\Delta \Delta G_{\text {bind }}$ was normalized according to 
a linear equation obtained in our previous work in which the correlations between various experimental and computed $\Delta \Delta G_{\text {bind }}$ values were determined ${ }^{48}$. Rotamer libraries used for computational modeling were based on the backbone-dependent library of Dunbrack and Karplus ${ }^{49}$, with additional rotamers expanded by 1 SD around their mean $\chi 1$ and $\chi^{2}$ values. For the calculations, we used ORBIT software with the energy function optimized for the design of protein-protein interactions ${ }^{48}$. The lowest-energy rotameric conformation of each mutated complex was found using the dead-end elimination theorem ${ }^{50,51}$.

Recombinant expression and purification of KLK4 variants. KLK4 ${ }_{\mathrm{WT}}$ (amino acid sequence and numbering are according to UniProtKB-Q9Y5K2) and selected KLK4 variants (KLK4 ${ }_{\mathrm{S} 207 \mathrm{~A}}$, KLK4 $4_{\mathrm{S} 207 \mathrm{~A}, \mathrm{E} 98 \mathrm{I}}$, $\mathrm{KLK}_{\mathrm{S} 207 \mathrm{~A}, \mathrm{E} 98 \mathrm{Y}}, \mathrm{KLK}_{\mathrm{S} 207 \mathrm{~A}, \mathrm{E} 98 \mathrm{~F}}, \mathrm{KLK}_{\mathrm{S} 207 \mathrm{~A}, \mathrm{~L} 185 \mathrm{E}}, \mathrm{KLK}_{\mathrm{S} 207 \mathrm{~A}, \mathrm{~L} 185 \mathrm{H}}, \mathrm{KLK}_{\mathrm{S} 207 \mathrm{~A}, \mathrm{~L} 185 \mathrm{Q}}$ and KLK4 $\left.4_{\mathrm{S} 207 \mathrm{~A}, \mathrm{~L} 185 \mathrm{D}}\right)$ were purified as previously described with minor modifications ${ }^{52}$. In brief, the pPIC9K plasmid (Invitrogen, CA, USA) containing the pro-KLK4 $4_{\mathrm{WT}}$ clone (with FLAG and His tags fused to the $\mathrm{N}$ - and C-termini of the protein, respectively) were isolated from individual Escherichia coli colonies by using a HiYield plasmid mini-kit (RBC Bioscience, Taiwan) and sequenced using primers 1 and 2 (Supplementary data Table S1). Point mutation S207A was introduced into the KLK4 ${ }_{\text {WT }}$ clone by using site-directed mutagenesis PCR with overlapping primers 3 and 4 (Supplementary Table S1) and PrimeSTAR HS DNA polymerase (Takara Bio, Otsu, Shiga, Japan). The parental methylated plasmid in the reaction (pPICK9K plasmid containing KLK4 ${ }_{\mathrm{WT}}$ ) was digested with the DpnI enzyme, according to the product protocol (New England Biolabs, MA, USA). The final product (containing only the linear dsDNA product) was electroporated into $E$. coli, incubated at $37^{\circ} \mathrm{C}$ with shaking at $300 \mathrm{rpm}$ for $1 \mathrm{~h}$ in LB medium ( $1 \%$ yeast extract w/v, $2 \%$ peptone w/v, $2 \%$ dextrose w/v), plated onto LB-Amp plates (ampicillin at $1 \mathrm{mg} / \mathrm{L}$ ), and then incubated at $37^{\circ} \mathrm{C}$ for $24 \mathrm{~h}$. Several colonies were scraped from the plate, transferred into LB-Amp medium, and incubated at $37^{\circ} \mathrm{C}$ with shaking at $300 \mathrm{rpm}$ for $24 \mathrm{~h}$. The pPIC9K plasmid containing the $\mathrm{KLK}_{\mathrm{S} 207 \mathrm{~A}}$ clone was then isolated from each $E$. coli colony with a HiYield plasmid mini-kit (RBC Bioscience) and sequenced using primers 1 and 2 (see Supplementary Table S1). KLK4 point mutations E98I, E98Y, E98F, L185S, L185Q, L185N, L185H, L185R, L185K, L185E and L185D were separately generated in the pPIC9K plasmid containing the KLK4 $4_{S 207 \mathrm{~A}}$ clone using the same procedure as that described above with primers 5-26, respectively (for example, E98I with primers 5 and 6; E98Y with primers 7 and 8 and so on; Supplementary Table S1). pPIC9K plasmids containing KLK4 mutants with the correct sequences were linearized using SacI, and $\sim 30 \mu \mathrm{g}$ of DNA was electroporated into P. pastoris strain GS115 (Invitrogen) for chromosomal incorporation by homologous recombination. Transformed cells were plated onto RDB plates (18.6\% sorbitol w/v, $2 \%$ agar w/v, 2\% dextrose w/v, 1.34\% yeast nitrogen base w/v, $4 \times 10^{-5} \%$ biotin w/v, $5 \times 10^{-3} \%$ of $\mathrm{L}$-glutamic acid, $\mathrm{L}$-methionine, L-leucine, L-lysine, L-isoleucine w/v) and incubated for three days at $30{ }^{\circ} \mathrm{C}$. Cells were scraped from the plates using E-buffer (0.12\% Tris base w/v, 9.24\% sucrose w/v and $0.02 \% \mathrm{MgCl}_{2} \mathrm{w} / \mathrm{v}$ at $\left.\mathrm{pH} 7.5\right)$ and plated onto YPD-G418 plates $(4 \mathrm{mg} / \mathrm{mL}$ G418) for an additional three days. Colonies $(\sim 10)$ from each clone were harvested, seeded into $5 \mathrm{~mL}$ of BMGY medium (2\% peptone w/v, $1 \%$ yeast extract w/v, $0.23 \% \mathrm{~K}_{2} \mathrm{H}\left(\mathrm{PO}_{4}\right)$ $\mathrm{w} / \mathrm{v}, 1.1812 \% \mathrm{KH}_{2}\left(\mathrm{PO}_{4}\right) \mathrm{w} / \mathrm{v}, 1.34 \%$ yeast nitrogen base $\mathrm{w} / \mathrm{v}, 4 \times 10^{-5} \%$ biotin $\mathrm{w} / \mathrm{v}, 1 \%$ glycerol $\left.\mathrm{v} / \mathrm{v}\right)$, and incubated at $30{ }^{\circ} \mathrm{C}$ with shaking at $300 \mathrm{rpm}$ for $24 \mathrm{~h}$. For protein expression, cells in BMGY medium were pelleted and then re-suspended in $5 \mathrm{~mL}$ of BMMY medium ( $2 \%$ peptone $\mathrm{w} / \mathrm{v}, 1 \%$ yeast extract w/v, $0.23 \% \mathrm{~K}_{2} \mathrm{H}\left(\mathrm{PO}_{4}\right) \mathrm{w} / \mathrm{v}$, $1.1812 \% \mathrm{KH}_{2}\left(\mathrm{PO}_{4}\right) \mathrm{w} / \mathrm{v}, 1.34 \%$ yeast nitrogen base w/v, $4 \times 10^{-5} \%$ biotin w/v, $\left.0.5 \% \mathrm{MeOH} \mathrm{v} / \mathrm{v}\right)$ to reach $\mathrm{OD}_{600}$ of 1.0 and incubated at $30^{\circ} \mathrm{C}$ with shaking at $300 \mathrm{rpm}$ for $72 \mathrm{~h}$, with $0.5 \% \mathrm{MeOH}$ being added every $24 \mathrm{~h}$. Protein expression and secretion into the medium were analyzed by western blot, using mouse anti-FLAG primary antibody (Sigma Aldrich, MO, USA) and an alkaline phosphatase conjugated anti-mouse secondary antibody (Jackson ImmunoResearch, PA, USA). BCIP reagent (Sigma Aldrich, MO, USA) was used for protein expression signal analysis according to the product protocol. Individual clones (representing each of the KLK4 variants) showing the strongest expression levels were selected and subjected to large-scale production and purification procedures. Briefly, clones in $5 \mathrm{~mL}$ of BMGY medium at $\mathrm{OD}_{600}$ of $8.0-10.0$ were added to $500 \mathrm{~mL}$ of BMGY medium at $30^{\circ} \mathrm{C}$ with shaking at $300 \mathrm{rpm}$ for $24 \mathrm{~h}$. Cells were precipitated from the medium and induced for protein secretion in $500 \mathrm{~mL}$ of $\mathrm{BMMY}$ at $30^{\circ} \mathrm{C}$ with shaking at $300 \mathrm{rpm}$ for $72 \mathrm{~h}$. $\mathrm{MeOH}(0.5 \%)$ was added to the medium every $24 \mathrm{~h}$. After induction, the supernatant was filtered through a $0.22-\mu \mathrm{m}$ vacuum filter. The filtrate was then subjected to the following workup: $\mathrm{NaCl}$ was added to a final concentration of $300 \mathrm{mM}$, imidazole (Sigma, MO, USA) was added to give a final concentration of $10 \mathrm{mM}$, and the solution $\mathrm{pH}$ was adjusted to 8.0. After $1 \mathrm{~h}$ at $4{ }^{\circ} \mathrm{C}$, the medium was filtered again, and the protein of interest was purified on a column packed with $5 \mathrm{~mL}$ of Ni-NTA Sepharose beads (Invitrogen). The protein was eluted from the Ni-NTA beads with $15 \mathrm{~mL}$ of buffer at $\mathrm{pH} 8.0$ containing $50 \mathrm{mM}$ sodium phosphate, $300 \mathrm{mM} \mathrm{NaCl}$ and $250 \mathrm{mM}$ imidazole. The eluted protein was concentrated to $5 \mathrm{~mL}$, and the buffer was replaced with PBS using a Vivaspin with a 5-kDa cutoff (Vivaproducts, MA, USA). The protein was then subjected to activation by thermolysin (Calbiochem, LaJolla, CA). Briefly, thermolysin, which cleaves the N'-terminus pro-domain, was added to KLK4 in a mass ratio of 1:80 (thermolysin:KLK4) for $2 \mathrm{~h}$ at $37^{\circ} \mathrm{C}$. The reaction was terminated by addition of 1,10 -phenanthroline at a final concentration of $10 \mathrm{mM}$. Activated KLK4 proteins were then purified using gel filtration chromatography on a Superdex $^{\text {tix }} 75$ 16/600 GL column in an ÄKTA ${ }^{\text {mu }}$ Pure (GE Biosciences, PA, USA) chromatography system. The gel filtration column was pre-equilibrated with PBS ( $\mathrm{pH} 7.4$ ), and the protein was eluted with PBS. The protein concentration was calculated from protein absorbance at $280 \mathrm{~nm}$ (extinction coefficient of $31,690 \mathrm{M}^{-1} \mathrm{~cm}^{-1}$ and calculated mass of $26.4 \mathrm{kDa}$ ) obtained using a NanoDrop spectrophotometer (Thermo Scientific, MA, USA). Non-activated protein samples (not treated with thermolysin), with theoretical mass of $28.6 \mathrm{kDa}$, were subjected to SDS-PAGE (denatured and reduced) and mass spectrometry analysis (Ilse Katz Institute for Nanoscale Science Technology, BGU). The purified proteins were stored at $-80^{\circ} \mathrm{C}$. 
Surface plasmon resonance (SPR) spectroscopy. The affinity constants for the interaction between the purified KLK4 variants and the PAR1 peptide were determined by SPR spectroscopy on a ProteOn XPR36 (Bio-Rad) instrument at the Cytometry, Proteomic and Microscopy Unit (NIBN, BGU). A biotinylated, PAR1 peptide (biotin ${ }^{31}$ SKATNATLDPRSFLLRNPNDKYEPFWED ${ }^{58}$-FITC, $>95 \%$, Peptron, Daejeon, Korea; residue numbering based on UniProtKB-P25116, PDB-ID 3LU9) was immobilized on the surface of an NLC chip (NeutrAvidin immobilized to a GLC layer) via NeutrAvidin-biotin interactions. The PAR1 peptide (26 $\mu \mathrm{g})$ dissolved in PBST (phosphate-buffered saline with $0.005 \%$ Tween 20) was immobilized on the chip to give 2600 response units (RU). An empty channel was used as the negative control. Prior to each binding assay, the temperature was set at $25{ }^{\circ} \mathrm{C}$. Purified KLK4 variants were then allowed to flow over the surface-bound PAR1 peptide at concentrations of $100,50,25,12.5,6.25$ and $0 \mathrm{nM}$ for $\mathrm{KLK} 4_{\mathrm{WT}}$, concentrations of 2, 1, 0.5, 0.25, 0.125 and $0 \mu \mathrm{M}$ for $\mathrm{KLK}_{\mathrm{S} 207 \mathrm{~A}}, \mathrm{KLK} 4_{\mathrm{S} 207 \mathrm{~A}, \mathrm{E} 981}, \mathrm{KLK}_{\mathrm{S} 207 \mathrm{~A}, \mathrm{E} 98 \mathrm{Y}}, \mathrm{KLK} 4_{\mathrm{S} 207 \mathrm{~A}, \mathrm{E} 98 \mathrm{~F}}, \mathrm{KLK}_{\mathrm{S} 207 \mathrm{~A}, \mathrm{~L} 185 \mathrm{E}}, \mathrm{KLK}_{\mathrm{S} 207 \mathrm{~A}, \mathrm{~L} 185 \mathrm{H}}$ and $\mathrm{KLK} 4_{\mathrm{S} 207 \mathrm{~A}, \mathrm{~L} 185 \mathrm{Q}}$, and concentrations of $8,4,2,1,0.5$ and $0 \mu \mathrm{M}$ for KLK4 $4_{S 207 \mathrm{~A}, \mathrm{~L} 185 \mathrm{D}}$, at a flow rate of $30 \mu \mathrm{L} / \mathrm{min}$ for $818 \mathrm{~s}$. The dissociation of the protein-peptide complex was then monitored with PBST flowing over the surface at a flow rate

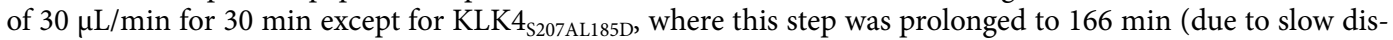
sociation). For each protein complex, a sensorgram was generated from the RUs measured during the course of the interaction minus the values of the empty channel. The values of $k_{o n}$ and $k_{\text {off }}$ were determined by fitting the sensorgrams to a 1:1 Langmuir kinetic model. The fitted data were considered statistically valid with a $\chi^{2}$ value that was less than the $10 \%$ of the RUmax in each of the fitted sensorgrams.

CD spectroscopy. To examine whether any structural change had been caused as a result of the mutations to KLK4, we evaluated the secondary structure of the selected purified non-activated KLK4 proteins by CD spectroscopy (J-815 CD spectrometer, JASCO, Tokyo, Japan, with a 1-mm path length quartz cuvette). Spectra of $10 \mu \mathrm{M}$ purified protein in $400 \mu \mathrm{L}$ of PBS were obtained at $25^{\circ} \mathrm{C}$, and the signal of the blank solvent (PBS) was subtracted. Ellipticity (degree $\times \mathrm{cm}^{2} / \mathrm{dmol}$ ) was obtained from the normalized average of four spectra in the range of 200-260 nm. Data points with a diode voltage above $1000 \mathrm{~V}$ were excluded.

Confocal microscopy. To follow the cleavage of full-length cell-expressed PAR1 by KLK $4_{\mathrm{WT}}$ and the inhibition of this cleavage by KLK4 $4_{\mathrm{S} 207 \mathrm{~A}, \mathrm{~L} 185 \mathrm{D}}$, we used the WM3682 human melanoma cell line (generously provided by Carmit Levi, Tel-Aviv University) or the MCF7 human breast cancer cell line (generously provided by Isam Khalaila, BGU). The cells were transfected with a fluorescently labeled PAR1 plasmid (pCDNA3.1 containing the mCherry-PAR1-eYFP construct described previously ${ }^{32}$ ) and Lipofectamine ${ }^{\text {tst }}$ LTX as a transfection reagent, according to product protocol (Thermo Scientific). For WM3682 cells, following $24 \mathrm{~h}$ of transfection, cells were sub-cultured in $\mu$-slide 8-well ibiTreat microscopy chambers (ibidi, Martinsried, Germany) in DMEM containing $10 \% \mathrm{FBS}$ and incubated for additional $24 \mathrm{~h}$ in a humidified incubator at $37{ }^{\circ} \mathrm{C}$ and $5 \% \mathrm{CO}_{2}$. Cells were washed once with PBS, suspended in FBS-free DMEM, and incubated for another $24 \mathrm{~h}$. Thereafter, the cells were treated with $100 \mathrm{nM} \mathrm{KLK} 4_{\mathrm{WT}}$ (positive control), with $200 \mathrm{nM} \mathrm{KLK} 4_{\mathrm{S} 207 \mathrm{~A}, \mathrm{~L} 185 \mathrm{D} \text {, with a combination of KLK4 }} 4_{\mathrm{WT}}$ and $\mathrm{KLK}_{\mathrm{S} 207 \mathrm{~A}, \mathrm{~L} 185 \mathrm{D}}$, or with medium alone (negative control) for $1 \mathrm{~h}$ under the same conditions as those prior to the analysis. Live fluorescence images were acquired with a confocal laser-scanning microscope (ZEISS LSM880 confocal microscope) using the Plan Apochromat $63 \times / 1.4$ oil DIC M27 objective (Ilse Katz Institute for Nanoscale Science and Technology Shared Resource Facility, BGU). The assay was performed in triplicate, and representative images are presented. For MCF7, the transfection was performed directly on the $\mu$-slide 8 -well ibiTreat microscopy chambers (ibidi) and after $24 \mathrm{~h}$, the medium was replaced with FBS-free DMEM and the cells were incubated for another $1 \mathrm{~h}$ in a humidified incubator at $37{ }^{\circ} \mathrm{C}$ and $5 \% \mathrm{CO}_{2}$. Thereafter, the cells were treated with $100 \mathrm{nM} \mathrm{KLK} 4_{\mathrm{WT}}, 200 \mathrm{nM} \mathrm{KLK} 4_{\mathrm{S} 207 \mathrm{~A}, \mathrm{~L} 185 \mathrm{D}}, 200 \mathrm{nM} \mathrm{KLK} 4_{\mathrm{S} 207 \mathrm{~A}}$, a combination of KLK $4_{\mathrm{WT}}$ and $\mathrm{KLK} 4_{\mathrm{S} 207 \mathrm{~A}, \mathrm{~L} 185 \mathrm{D}}$ or $\mathrm{KLK} 4_{\mathrm{WT}}$ and $\mathrm{KLK} 4_{\mathrm{S} 207 \mathrm{~A}}$, or with medium alone (negative control) for $1 \mathrm{~h}$ and incubated under the same conditions as those prior to the analysis. Cells were washed once with PBS, then fixed in $4 \%$ paraformaldehyde in PBS for $10 \mathrm{~min}$ at room temperature, washed again, and covered with PBS. Fluorescent samples were imaged using an FV1000 laser scanning confocal microscope (Olympus) with 488 and $561 \mathrm{~nm}$ solid state lasers and $\mathrm{a} \times 40 / 1.25 \mathrm{NA}$ silicon immersion objective (NIBN, BGU). Fluorescence images were acquired using the Flowview 10 ASW V2.1 software. The assay was performed in two replications (separate wells for each condition), and two fields from each well were examined.

Monitoring the KLK4-mediated release of the N-terminal mCherry PAR1 tag. Two T25 flasks of confluent WM3682 cells were transfected with the mCherry-PAR1-YFP construct described previously ${ }^{32}$ and incubated for $24 \mathrm{~h}$ at $37^{\circ} \mathrm{C}$ in a humidified incubator in an atmosphere of $5 \% \mathrm{CO}_{2}$ in room air. Transfected cells grown to confluency in the two T25 flasks were then lifted with $0.25 \%$ trypsin in $1 \mathrm{mM}$-EDTA-supplemented PBS, pH 7.4. Cells were combined and subcultured in a 48 -well multi-dish tray (Nunc $1 \mathrm{~cm}^{2}$ area) in $10 \%$ serum-supplemented DMEM and incubated for a further $24 \mathrm{~h}$. Cells were serum starved by replacing the culture medium with $0.2 \mathrm{~mL}$ of serum-free DMEM containing $0.1 \%$ bovine serum albumin (BSA) and incubated overnight. The next day, cells were washed 3 times with isotonic Hanks' balanced salt solution $\mathrm{pH} 7.4$ containing $10 \mathrm{mM}$ HEPES, $1.5 \mathrm{mM} \mathrm{MgCl}_{2}, 1.5 \mathrm{mM} \mathrm{CaCl}_{2}$, and $0.1 \%$ BSA and replenished with $0.1 \mathrm{~mL}$ of the same buffer. $\mathrm{KLK} 4_{\mathrm{WT}}$ and KLK $4_{\mathrm{S} 207 \mathrm{~A}, \mathrm{~L} 185 \mathrm{D}}$ were mixed and preincubated for $1 \mathrm{~h}$ on ice at 10 times the final specified concentration added to the cells. In each well, $10 \mu \mathrm{L}$ of pre-incubated $10 \times$ enzyme mix was then added to the indicator cell monolayer containing $90 \mu \mathrm{L}$ of buffer and incubated for $30 \mathrm{~min}$ at $37^{\circ} \mathrm{C}$. The supernatant was transferred to a 96-well multiwell plate and the intensity of fluorescence (excitation $560 \mathrm{~nm} / \mathrm{emission} 620 \mathrm{~nm}$ ) generated by the released mCherry tag was measured using SpectraMax i3X plate reader (Molecular Devices, San Jose, CA). The data show the average fluorescence \pm SEM (bars) from 4 replicate wells relative to the signal generated by $1 \mathrm{U} /$ 
$\mathrm{mL}$ thrombin $(10 \mathrm{nM})$. The statistical difference for data obtained from the untreated vs. KLK $4_{\text {S207A,L185D }}$ treated cells was determined by a one-way ANOVA for measurements performed for four cell monolayer replicates.

PAR1 cell expression. The expression levels of PAR1 in WM3682 and WM3314 cells were determined using flow cytometry. In brief, $0.3 \times 10^{6}$ cells were seeded in a 6-well plate in DMEM containing $10 \%$ FBS and incubated in a humidified incubator at $37^{\circ} \mathrm{C}$ and $5 \% \mathrm{CO}_{2}$ until reaching $80 \%$ confluence. The cells were then washed with a flow-cytometry buffer (0.1\% BSA in PBS), harvested using a cell scraper, and incubated for $30 \mathrm{~min}$ in a flow-cytometry buffer or in a flow-cytometry buffer containing anti PAR1 Alexa Fluor 680 conjugated antibody $\left(1 \mu \mathrm{g}\right.$ per $1 \times 10^{6}$ cells, ATAP2 clone, Santa Cruz, CA, USA). Cells were washed once with a flowcytometry buffer and analyzed using a flow cytometer. For the negative control, the same procedure was carried out with one exception: $0.25 \%$ trypsin solution was used to detach the cells from the 6-well plate (instead of a cell scraper). Analysis was carried out on an Accuri C6 Flow Cytometer (BD Biosciences, CA, USA), and data analysis was performed using a FlowJo software (Treestar, Inc., CA, USA).

Migration assay. Testing the inhibition by KLK4 $4_{\text {S207A,L185D }}$ of the migratory phenotype of the WM3682 cell line was performed by using a scratch assay, as previously described ${ }^{53}$. Briefly, WM3682 cells $\left(1.5 \times 10^{5}\right)$ were cultured as confluent monolayers in a 24-well plate in DMEM containing 10\% FBS and incubated in a humidified incubator at $37^{\circ} \mathrm{C}$ and $5 \% \mathrm{CO}_{2}$. When the cells reached $100 \%$ confluence, a scratch was formed by removing a strip of cells across the well with a p200 pipette tip. The scratched monolayers were then washed twice with PBS to remove non-adherent cells, and $500 \mu \mathrm{L}$ of DMEM supplemented with $2 \%$ FBS, containing 12.5, 25, or $200 \mathrm{nM}$ KLK4 $4_{\text {S207A,L185D }}$ or PBS (control), was added. The wells were captured with an EVOS FL cell imaging system at $\times 4$ magnification, both immediately after cell wounding $\left(\mathrm{t}_{0}\right)$ and again after $24 \mathrm{~h}\left(\mathrm{t}_{24}\right)$. The experiment was performed in triplicate, and the images were analyzed using ImageJ software. The ratio between the gap areas at $\mathrm{t}_{0}$ and $\mathrm{t}_{24}$ was calculated.

Invasion assay. An in-vitro Boyden chamber assay was performed as previously described with minor changes $^{53}$. Briefly, ThinCert 24-well cell culture inserts (Greiner Bio-One, Germany) were coated with growth factor reduced Matrigel (Corning, NY, USA) diluted in DMEM (Biological Industries, Israel) at a 1:30 v/v ratio. The lower chamber was filled with $600 \mu \mathrm{L}$ of DMEM supplemented with 10\% FBS (Biological Industries, Israel). WM3314 cells $\left(12.5 \times 10^{5}\right.$, generously provided by Carmit Levi, Tel-Aviv University), in the presence or absence of KLK4 $4_{\text {S207A,L185D }}$ protein, were incubated in $200 \mu \mathrm{L}$ of FBS-free DMEM, added to the pre-coated ThinCert cell culture inserts, and incubated for $18 \mathrm{~h}$ at $37^{\circ} \mathrm{C}$ and $5 \% \mathrm{CO}_{2}$. Invasive cells were stained with a DippKwik stain kit (American MasterTech Scientific) and detected by an EVOS FL Cell Imaging System (Life Technologies, Carlsbad, CA, USA), at $\times 4$ magnification. The experiment was performed in triplicate, and the images were taken from the center field of each insert. Analysis of digitized images was performed using ImageJ software and a Cell Colony Edge Analyser.

ERK phosphorylation assay. The experiment was performed using the WM3682 cell line as previously described with minor modifications ${ }^{54}$. The cells were grown in complete DMEM (Biological Industries) containing $10 \%$ FBS, penicillin, streptomycin, and L-glutamine until they reached $80 \%$ confluence. Cells were scraped with a cell scraper, diluted 1:2, and grown overnight in complete DMEM. Thereafter, $2.5 \times 10^{5}$ cells were transferred into a 12-well plate with complete DMEM for $24 \mathrm{~h}$. At this point, the medium was replaced with a starvation medium (FBS-free complete DMEM) for $18 \mathrm{~h}$. After starvation, the cells were washed with PBS and incubated in a starvation medium containing $10 \mathrm{nM} \mathrm{KLK} 4_{\mathrm{WT}}$ and 0, 10, 100 and $1000 \mathrm{nM} \mathrm{KLK} 4_{S 207 \mathrm{~A}, \mathrm{~L} 185 \mathrm{D}}$ in a humidified incubator at $37^{\circ} \mathrm{C}$ and $5 \% \mathrm{CO}_{2}$ for $15 \mathrm{~min}$. The positive control contained $10 \mathrm{nM} \mathrm{KLK} 4_{\mathrm{WT}}$ alone, and the negative control was incubated in starvation medium without any added protein. The cells were transferred to ice, and a lysis buffer [deoxycholate $0.5 \%, 25 \mathrm{nM} \mathrm{NaF}, 10 \mathrm{mM} \mathrm{Na} 2 \mathrm{PO}_{4}, 1 \mathrm{mM}$ sodium orthovanadate, $5 \mathrm{mM}$ EDTA (pH 7.4), 5 mM EGTA (pH 7.4), $100 \mathrm{mM} \mathrm{NaCl}, 2 \%$ Triton X-100, 2\% $p$-nitrophenyl phosphate (PNPP) and a protease inhibitor cocktail (A2S, Israel)] was added. The cells were detached with a cell scraper, collected, incubated on ice for $10 \mathrm{~min}$, and centrifuged at 14,000 g for $30 \mathrm{~min}$, and the supernatants were transferred to fresh tubes. Western blot analysis was performed for all samples using anti-MAP kinase (Erk1/2) produced in rabbit or anti-MAP kinase, activated (diphosphorylated Erk1/2) antibody produced in mouse as a primary antibody (Sigma, MA, USA). A secondary HRP-linked anti-rabbit or anti-mouse antibody was then added, and the signal was developed using the EZ-ECL kit (Biological Industries). The chemiluminescent signal was imaged with Fusion FX (Vilber Lourmat, Germany). Equal amounts of total protein from cell lysate samples were loaded in each lane on the SDS-PAGE, as measured by a colorimetric BCA protein assay kit (Pierce Biotechnology, Rockford, IL, USA). The experiment was performed in triplicate, and a representative membrane image was selected for presentation.

Cell viability assay. The effects of KLK4 $4_{\mathrm{S} 207 \mathrm{~A}, \mathrm{~L} 185 \mathrm{D}}$ on the growth and survival of WM3682 and MCF7 cells were assessed by an XTT assay (2,3-bis [2-methoxy-4-nitro-5-sulfophenyl]-2H-tetrazolium-5-carboxanilide inner salt assay; Biological Industries). WM3682 or MCF7 cells were seeded (7500 cells per well) in a 96 -well microplate (R\&D Systems, MN, USA) and incubated at $37^{\circ} \mathrm{C}$ at $5 \% \mathrm{CO}_{2}$ for $24 \mathrm{~h}$. The medium was then replaced with fresh DMEM supplemented with $10 \%$ FBS, penicillin, streptomycin, and L-glutamine, and the cells were incubated for $24 \mathrm{~h}$ at $37^{\circ} \mathrm{C}$ at $5 \% \mathrm{CO}_{2}$ in the presence or absence of $1 \mu \mathrm{M} \mathrm{KLK} 4_{\mathrm{S} 207 \mathrm{~A}, \mathrm{~L} 185 \mathrm{D} \text {. Viable cells from each }}$ condition were measured by reading the absorbance at $450 \mathrm{~nm}$ (UV), using a plate reader, as described in the manufacturer's protocol. The UV readings of the cell-only control were normalized to $100 \%$, and readings from cells treated with $\mathrm{KLK} 4_{\mathrm{S} 207 \mathrm{~A}, \mathrm{~L} 185 \mathrm{D}}$ were presented as a percentage of the control. 
Statistical analysis. Data were analyzed with GraphPad Prism version 5.00 for Windows (La Jolla, CA). Data shown in all the figures are the means of triplicates from independent experiments, and error bars represent the standard error of the mean. Statistical significance was determined by column statistics and one-way ANOVA analysis. A $p$ value $<0.05$ was considered statistically significant.

Received: 2 February 2021; Accepted: 29 July 2021

Published online: 09 August 2021

\section{References}

1. Hollenberg, M. D. \& Compton, S. J. International Union of Pharmacology XXVIII. Proteinase-activated receptors. Pharmacol Rev 54, 203-217. https://doi.org/10.1124/pr.54.2.203 (2002).

2. Vu, T. K. H., Hung, D. T., Wheaton, V. I. \& Coughlin, S. R. Molecular cloning of a functional thrombin receptor reveals a novel proteolytic mechanism of receptor activation. Cell https://doi.org/10.1016/0092-8674(91)90261-V (1991).

3. Oikonomopoulou, K. et al. Proteinase-activated receptors, targets for kallikrein signaling. J. Biol. Chem. 281, 32095-32112 (2006).

4. Gratio, V. et al. Kallikrein-related peptidase 4: a new activator of the aberrantly expressed protease-activated receptor 1 in colon cancer cells. Am. J. Pathol. 176, 1452-1461 (2010).

5. Fujimoto, D., Hirono, Y., Goi, T., Katayama, K. \& Yamaguchi, A. Prognostic value of protease-activated receptor-1 (PAR-1) and matrix metalloproteinase-1 (MMP-1) in gastric cancer. Anticancer Res. 28, 847-854 (2008).

6. Ludeman, M. J. et al. PAR1 cleavage and signaling in response to activated protein C and thrombin. J. Biol. Chem. 280, 13122-13128 (2005).

7. Kahn, M. L., Nakanishi-Matsui, M., Shapiro, M. J., Ishihara, H. \& Coughlin, S. R. Protease-activated receptors 1 and 4 mediate activation of human platelets by thrombin. J. Clin. Investig. 103, 879-887 (1999).

8. Cunningham, M. A. et al. Protease-activated receptor 1 mediates thrombin-dependent, cell-mediated renal inflammation in crescentic glomerulonephritis. J. Exp. Med. 191, 455-462 (2000).

9. Kahn, M. L. et al. A dual thrombin receptor system for platelet activation. Nature 394, 690-690 (1998).

10. Cunningham, B. C. \& Wells, J. A. High-resolution epitope mapping of hGH-receptor interactions by alanine-scanning mutagenesis. Science https://doi.org/10.1126/science.2471267 (1989).

11. Kalz, J., Ten Cate, H. \& Spronk, H. M. H. Thrombin generation and atherosclerosis. J. Thromb. Thrombolysis 37, 45-55 (2014).

12. Andrade-Gordon, P. et al. Administration of a potent antagonist of protease-activated receptor-1 (PAR-1) attenuates vascular restenosis following balloon angioplasty in rats. J. Pharmacol. Exp. Ther. 298, 34-42 (2001).

13. Zhang, P. et al. Suppression of arterial thrombosis without affecting hemostatic parameters with a cell-penetrating PAR1 pepducin. Circulation 126, 83-91 (2012).

14. Cisowski, J. et al. Targeting protease-activated receptor-1 with cell-penetrating pepducins in lung cancer. Am. J. Pathol. 179, 513-523 (2011).

15. Black, P. C. et al. Overexpression of protease-activated receptors-1,-2, and -4 (PAR-1, -2, and -4) in prostate cancer. Prostate https:// doi.org/10.1002/pros.20503 (2007).

16. Grisaru-Granovsky, S. et al. Differential expression of protease activated receptor 1 (Par1) and pY397FAK in benign and malignant human ovarian tissue samples. Int. J. Cancer 113, 372-378 (2005).

17. Zigler, M., Kamiya, T., Brantley, E. C., Villares, G. J. \& Bar-Eli, M. PAR-1 and thrombin: the ties that bind the microenvironment to melanoma metastasis. Can. Res. 71, 6561-6566 (2011).

18. Blackburn, J. S., Liu, I., Coon, C. I. \& Brinckerhoff, C. E. A matrix metalloproteinase-1/protease activated receptor-1 signaling axis promotes melanoma invasion and metastasis. Oncogene 28, 4237-4237 (2009).

19. Boire, A. et al. PAR1 Is a Matrix Metalloprotease-1 Receptor that Promotes Invasion and Tumorigenesis of Breast Cancer Cells. Cell 120, 303-313. https://doi.org/10.1016/j.cell.2004.12.018 (2005).

20. Wang, F.-Q., Fisher, J. \& Fishman, D. A. MMP-1-PAR1 axis mediates LPA-induced epithelial ovarian cancer (EOC) invasion. Gynecol. Oncol. 120, 247-255 (2011).

21. Zhu, L. et al. Cooperation of protease-activated receptor 1 and integrin $\alpha v \beta 5$ in thrombin-mediated lung cancer cell invasion. Oncol. Rep. 28, 553-560 (2012).

22. Villares, G. J. et al. Targeting melanoma growth and metastasis with systemic delivery of liposome-incorporated protease-activated receptor-1 small interfering RNA. Can. Res. 68, 9078-9086 (2008).

23. Adams, G. N. et al. Colon cancer growth and dissemination relies upon thrombin, stromal PAR-1, and fibrinogen. Can. Res. 75 , 4235-4243 (2015).

24. Filippou, P. S., Karagiannis, G. S., Musrap, N. \& Diamandis, E. P. Kallikrein-related peptidases (KLKs) and the hallmarks of cancer. Crit Rev Clin Lab Sci 53, 277-291. https://doi.org/10.3109/10408363.2016.1154643 (2016).

25. Furio, L. \& Hovnanian, A. Netherton syndrome: defective kallikrein inhibition in the skin leads to skin inflammation and allergy. Biol Chem 395, 945-958. https://doi.org/10.1515/hsz-2014-0137 (2014).

26. Prassas, I., Eissa, A., Poda, G. \& Diamandis, E. P. Unleashing the therapeutic potential of human kallikrein-related serine proteases. Nat Rev Drug Discov 14, 183-202. https://doi.org/10.1038/nrd4534 (2015).

27. Di Paolo, C. T. et al. Screening of chemical libraries in pursuit of kallikrein-5 specific inhibitors for the treatment of inflammatory dermatoses. Clin Chem Lab Med 57, 1737-1743. https://doi.org/10.1515/cclm-2019-0123 (2019).

28. Ramsay, A. J. et al. Kallikrein-related peptidase 4 (KLK4) initiates intracellular signaling via protease-activated receptors (PARs). KLK4 and PAR-2 are co-expressed during prostate cancer progression. J Biol Chem 283, 12293-12304, doi:https://doi.org/10.1074/ jbc.M709493200 (2008).

29. Kryza, T. et al. Kallikrein-related peptidase 4 induces cancer-associated fibroblast features in prostate-derived stromal cells. Mol Oncol 11, 1307-1329. https://doi.org/10.1002/1878-0261.12075 (2017).

30. Rei Liao, J. Y. \& van Wijk, K. J. Discovery of AAA+ Protease Substrates through Trapping Approaches. Trends Biochem Sci 44, 528-545, doi:https://doi.org/10.1016/j.tibs.2018.12.006 (2019).

31. Dong, Y. et al. Metastasis of ovarian cancer is mediated by kallikrein related peptidases. Clin. Exp. Metas. 31, 135-147 (2014).

32. Mihara, K., Ramachandran, R., Renaux, B., Saifeddine, M. \& Hollenberg, M. D. Neutrophil elastase and proteinase-3 trigger G protein-biased signaling through proteinase-activated receptor-1 (PAR1). J. Biol. Chem. 288, 32979-32990 (2013).

33. Wang, W., Mize, G. J., Zhang, X. \& Takayama, T. K. Kallikrein-related peptidase-4 initiates tumor-stroma interactions in prostate cancer through protease-activated receptor-1. Int. J. Cancer https://doi.org/10.1002/ijc.24904 (2010).

34. Tanimura, S. \& Takeda, K. ERK signalling as a regulator of cell motility. J. Biochem. 162, 145-154 (2017).

35. Villares, G. J., Zigler, M. \& Bar-Eli, M. The emerging role of the thrombin receptor (PAR-1) in melanoma metastasis-a possible therapeutic target. Oncotarget 2, 8-8 (2011). 
36. Wang, Q. M., Lv, L., Tang, Y., Zhang, L. \& Wang, L. F. MMP-1 is overexpressed in triple-negative breast cancer tissues and the knockdown of MMP-1 expression inhibits tumor cell malignant behaviors in vitro. Oncol. Lett. 17, 1732-1740 (2019).

37. Zhang, R. et al. Golgi Membrane Protein 1 (GOLM1) promotes growth and metastasis of breast cancer cells via regulating matrix metalloproteinase-13 (MMP13). Med. Sci. Monitor: Int. Med. J. Exp. Clin. Res. 25, 847-847 (2019).

38. Ehrenfeld, P. et al. Bioregulation of Kallikrein-related Peptidases 6,10 and 11 by the Kinin B1 Receptor in Breast Cancer Cells. Anticancer Res. 34, 6925-6938 (2014).

39. Ramachandran, R., Altier, C., Oikonomopoulou, K. \& Hollenberg, M. D. Proteinases, their extracellular targets, and inflammatory signaling. Pharmacol Rev 68, 1110-1142. https://doi.org/10.1124/pr.115.010991 (2016).

40. Debela, M. et al. Structures and specificity of the human kallikrein-related peptidases KLK 4, 5, 6, and 7. Biol. Chem. 389, 623-632 (2008).

41. Han, X., Bouck, E. G., Zunica, E. R., Arachiche, A. \& Nieman, M. T. (ed Alan D. B. T. Platelets Michelson) 243-257 (Academic Press, 2019).

42. Gandhi, P. S., Chen, Z. \& Di Cera, E. Crystal structure of thrombin bound to the uncleaved extracellular fragment of PAR1. J. Biol. Chem. https://doi.org/10.1074/jbc.M110.115337 (2010).

43. Riley, B. T. et al. Direct and indirect mechanisms of KLK4 inhibition revealed by structure and dynamics. Sci. Rep. 6, 35385-35385 (2016).

44. Webb, B. \& Sali, A. Comparative Protein Structure Modeling Using MODELLER. Curr Protoc Bioinform. 47, 56 1-32, doi:https:// doi.org/10.1002/0471250953.bi0506s47 (2014).

45. London, N., Raveh, B., Cohen, E., Fathi, G. \& Schueler-Furman, O. Rosetta FlexPepDock web server: high resolution modeling of peptide-protein interactions. Nucleic Acids Res. https://doi.org/10.1093/nar/gkr431 (2011).

46. Raveh, B., London, N. \& Schueler-Furman, O. Sub-angstrom modeling of complexes between flexible peptides and globular proteins. Proteins: Struct. Funct. Bioinform. doi:https://doi.org/10.1002/prot.22716 (2010).

47. Chen, V. B. et al. MolProbity: all-atom structure validation for macromolecular crystallography. Acta Crystallogr. D Biol. Crystallogr. https://doi.org/10.1107/S0907444909042073 (2010).

48. Sharabi, O., Dekel, A. \& Shifman, J. M. Triathlon for energy functions: Who is the winner for design of protein-protein interactions?. Proteins: Struct. Funct. Bioinform. https://doi.org/10.1002/prot.22977 (2011).

49. Dunbrack, R. L. Jr. \& Karplus, M. Backbone-dependent rotamer library for proteins application to side-chain prediction. J. Mol. Biol. 230, 543-574 (1993).

50. Desmet, J., De Maeyer, M., Hazes, B. \& Lasters, I. The dead-end elimination theorem and its use in protein side-chain positioning. Nature 356, 539-539 (1992).

51. Gordon, D. B., Hom, G. K., Mayo, S. L. \& Pierce, N. A. Exact rotamer optimization for protein design. J. Comput. Chem. https:// doi.org/10.1002/jcc.10121 (2003).

52. Rabinovich, E. et al. Identifying residues that determine SCF molecular-level interactions through a combination of experimental and in silico analyses. J. Mol. Biol. 429, 97-114 (2017).

53. Shlamkovich, T., Aharon, L., Koslawsky, D., Einav, Y. \& Papo, N. Targeting the Tie2- $\alpha$ v $\beta 3$ integrin axis with bi-specific reagents for the inhibition of angiogenesis. BMC Biol. 16, 92-92 (2018).

54. Zur, Y. et al. Engineering a monomeric variant of macrophage colony-stimulating factor (M-CSF) that antagonizes the c-FMS receptor. Biochemical Journal 474, 2601-2617 (2017).

\section{Acknowledgements}

The authors thank Dr. Uzi Hadad for his technical assistance and Prof. Carmit Levi and Dr. Isam Khalaila for providing cells. Flow-cytometry experiments were performed at the Ilse Katz Institute for Nanoscale Science \& Technology. N.P. acknowledges support from the European Research Council "Ideas program" ERC-2013-StG (contract grant number: 336041) and the US-Israel Binational Science Foundation (BSF). Studies were also supported in part by a Grant from the Canadian Institutes of Health Research (to M.H.).

\section{Author contributions}

E.R. and N.P. designed the research; E.R. performed the research; E.R. and N.P. analyzed the data; M.Z. and A.A. produced proteins; M.H. and J.S. performed the bioinformatics analysis; K.M. and M.D.H. generated the stable cells and performed the mCherry PAR1 tag release experiment; A.S. performed SPR experiments. E.R. and N.P. wrote the paper. All authors edited the manuscript and approved the final version.

\section{Competing interests}

The authors declare no competing interests.

\section{Additional information}

Supplementary Information The online version contains supplementary material available at https://doi.org/ 10.1038/s41598-021-95666-4.

Correspondence and requests for materials should be addressed to N.P.

Reprints and permissions information is available at www.nature.com/reprints.

Publisher's note Springer Nature remains neutral with regard to jurisdictional claims in published maps and institutional affiliations.

(c) (i) Open Access This article is licensed under a Creative Commons Attribution 4.0 International cc) License, which permits use, sharing, adaptation, distribution and reproduction in any medium or format, as long as you give appropriate credit to the original author(s) and the source, provide a link to the Creative Commons licence, and indicate if changes were made. The images or other third party material in this article are included in the article's Creative Commons licence, unless indicated otherwise in a credit line to the material. If material is not included in the article's Creative Commons licence and your intended use is not permitted by statutory regulation or exceeds the permitted use, you will need to obtain permission directly from the copyright holder. To view a copy of this licence, visit http://creativecommons.org/licenses/by/4.0/.

(C) The Author(s) 2021 